\title{
CAMA
}

Centre for Applied Macroeconomic Analysis

\section{A Macroprudential Stable Funding Requirement and Monetary Policy in a Small Open Economy}

\section{CAMA Working Paper 23/2016 May 2016}

\section{Punnoose Jacob}

Reserve Bank of New Zealand and

Centre for Applied Macroeconomic Analysis, ANU

\section{Anella Munro}

Reserve Bank of New Zealand and

Centre for Applied Macroeconomic Analysis, ANU

\section{Abstract}

The Basel III net stable funding requirement, scheduled for adoption in 2018, requires banks to use a minimum share of long-term wholesale funding and deposits to fund their assets. A similar regulation has been in place in New Zealand since 2010. This paper introduces the stable funding requirement (SFR) into a DSGE model featuring a banking sector with richly-specified liabilities, and estimates the model for New Zealand. We then evaluate the implications of an SFR for monetary policy trade-offs. Altering the steadystate SFR does not materially affect the transmission of most structural shocks to the real economy and hence has little effect on the optimised monetary policy rules. However, a higher steady-state SFR level amplifies the effects of bank funding shocks, adding to macroeconomic volatility and worsening monetary policy trade-offs conditional on these shocks. We find that this volatility can be moderated if optimal monetary or prudential policy responds to credit growth. 


\section{Keywords}

DSGE models, prudential policy, monetary policy, small open economy, sticky interest rates, banks, wholesale funding

\section{JEL Classification}

E31, E32, E44, F41

\section{Address for correspondence:}

(E) cama.admin@anu.edu.au

ISSN 2206-0332

The Centre for Applied Macroeconomic Analysis in the Crawford School of Public Policy has been established to build strong links between professional macroeconomists. It provides a forum for quality macroeconomic research and discussion of policy issues between academia, government and the private sector.

The Crawford School of Public Policy is the Australian National University's public policy school, serving and influencing Australia, Asia and the Pacific through advanced policy research, graduate and executive education, and policy impact. 


\title{
A Macroprudential Stable Funding Requirement and Monetary Policy in a Small Open Economy*
}

\author{
Punnoose Jacob ${ }^{1,2}$ and Anella Munro ${ }^{1,2}$ \\ ${ }^{1}$ Reserve Bank of New Zealand \\ ${ }^{2}$ Centre for Applied Macroeconomic Analysis - Australian National University
}

April 23, 2016

\begin{abstract}
The Basel III net stable funding requirement, scheduled for adoption in 2018, requires banks to use a minimum share of long-term wholesale funding and deposits to fund their assets. A similar regulation has been in place in New Zealand since 2010. This paper introduces the stable funding requirement (SFR) into a DSGE model featuring a banking sector with richly-specified liabilities, and estimates the model for New Zealand. We then evaluate the implications of an SFR for monetary policy trade-offs. Altering the steady-state SFR does not materially affect the transmission of most structural shocks to the real economy and hence has little effect on the optimised monetary policy rules. However, a higher steady-state SFR level amplifies the effects of bank funding shocks, adding to macroeconomic volatility and worsening monetary policy trade-offs conditional on these shocks. We find that this volatility can be moderated if optimal monetary or prudential policy responds to credit growth.
\end{abstract}

JEL classification: E31, E32, E44, F41

Keywords: DSGE models, Prudential policy, Monetary policy, Small open economy, Sticky interest rates, Banks, Wholesale funding

*Jacob: Punnoose.Jacob@rbnz.govt.nz. Munro: Anella.Munro@rbnz.govt.nz. The views expressed herein do not necessarily reflect those of the Reserve Bank of New Zealand. We thank Glenn Otto, Massimiliano Pisani, Christie Smith, Lenno Uusküla, participants at the Melbourne Institute Macroeconomic Policy Meeting 2015 and the Central Bank Macroeconomic Modelling Workshop 2015, and seminar participants at the Bank of Estonia and the Bank for International Settlements for helpful suggestions. 


\section{Introduction}

Central banks act as lenders of last resort to prevent liquidity pressures from becoming solvency problems. Liquidity provision by central banks, however, can lead to the problem of moral hazard. The availability of public liquidity reduces the incentive for banks to raise relatively expensive 'stable' funding such as retail deposits and long-term bonds, and leads banks to underinsure against refinancing risk. In periods when credit has grown rapidly, retail deposits have tended to grow more slowly, and banks have shifted toward less stable funding from short-term wholesale markets. As discussed in Shin and Shin (2011), the shift toward short-term wholesale funding increases the exposure of the banking system to refinancing risk, both by increasing rollover requirements and by lengthening intermediation chains through funding from other financial institutions. In response to the systemic liquidity stress experienced during the recent global financial crisis, extensive liquidity support was provided to banks, reinforcing incentives for moral hazard. Hence, stronger liquidity regulation has been proposed to increase banks' selfinsurance against liquidity risk.

The Basel III liquidity regulations, scheduled to come into force in 2018, include a net stable funding ratio (NSFR) that requires banks to raise a share of funding from more stable retail deposits and long-term wholesale funding, rather than short-term wholesale funding. In April 2010, New Zealand adopted a core funding requirement that is similar in spirit to the Basel III NSFR. ${ }^{1}$ In this paper, we draw on New Zealand's experience with the core funding requirement, to examine the macroeconomic consequences of the stable funding requirement, focussing in particular on the monetary policy implications.

We introduce the stable funding requirement into a fairly standard DSGE model with nominal rigidities and then examine how the new prudential policy alters macroeconomic dynamics and consequently, monetary policy trade-offs. Central to our modelling strategy is the design of a banking sector with disaggregated liabilities: retail deposits, and

\footnotetext{
${ }^{1}$ The Basel III NSFR is defined as the ratio of available stable funding to required stable funding (see www.bis.org/publ/bcbs189.pdf). The New Zealand core funding ratio (CFR) is defined as the ratio of stable funding to loans and advances (see www.rbnz.govt.nz/regulationandsupervision/banks/ prudentialrequirements/4664431.html). Although the definitions differ in details and in calibration, they are broadly equivalent. The numerator includes deposits, long-term wholesale funding and equity, and excludes short-term wholesale funding. The denominator includes loans, which are typically illiquid, and excludes more liquid assets. The Basell III NSFR as well as the New Zealand CFR are part of broader liquidity regulations that include liquid asset requirements and maturity mismatch limits.
} 
short-term and long-term wholesale funding. The stable funding requirement regulates the proportion of deposits and long-term liabilities on the bank's balance-sheet and a deviation from the required proportion of stable funding is subject to a penalty function. ${ }^{2}$

We show the history of the core funding ratio in New Zealand in Panel (a) of Figure 1. Before the regulation was put in place in April 2010, New Zealand banks used stable funding due to internal risk management considerations or implicit requirements imposed by creditors and rating agencies. This provides us with a time series on the stable funding ratio, which, along with other key macroeconomic and financial series, facilitates the estimation of the DSGE model. We estimate the model with Bayesian methods using quarterly data over 1998 to 2014.

The estimated model is used to evaluate the implications of the macroprudential instrument for monetary policy trade-offs. We examine its effects on loss-minimising policy rules derived from varied specifications of the central bank's monetary policy loss function. Taking into account the influence of all the estimated structural shocks, the presence of the stable funding requirement makes little difference to loss-minimising monetary policy rules. However the picture is starkly different in the case of the shock to the funding spread which affects long-term financing.

It is well known that credit spreads are compressed during booms and expand during recessions. ${ }^{3}$ As shown in Panel (b) of Figure 1, New Zealand dollar wholesale funding spreads were low during the build-up to the global financial crisis and rose sharply during the crisis. $^{4}$ In our model, the spread component must be carried for the duration of the funding because it cannot be hedged, unlike the benchmark interest rate. A stable funding requirement that increases the share of long-term funding in banks' balance sheets increases the banks' exposure to shocks in the long-term bond market. This feature of the policy instrument makes it an amplifier of the transmission of spread shocks; if a higher proportion of banks' liabilities are held in long-term bonds when the spreads on these bonds rise, the upward pressure on domestic lending rates is stronger and hence

\footnotetext{
${ }^{2} \mathrm{~A}$ previous draft of this paper circulated under the title 'The macroeconomic effects of a stable funding requirement' studied a similar banking sector set-up involving long-term debt and deposits in a calibrated real business cycle model. We thank Chris Bloor and Rebecca Craigie for contributions in the early stages of the project.

${ }^{3}$ See e.g. Christiano, Motto, and Rostagno (2014) for the US experience.

${ }^{4}$ Long-term funding spreads can be important for the commercial banks because they are larger and more variable than short-term spreads. See Acharya and Skeie (2011) for a theoretical discussion.
} 
economic activity contracts further. The macroeconomic volatility that is generated by this mechanism worsens monetary policy trade-offs. We find that this additional volatility can be moderated if monetary and prudential policy respond directly to various measures of credit growth. ${ }^{5}$

The paper lies at the interface of several strands of the literature. The first is the theoretical literature that explicitly incorporates financial regulation into macroeconomic models, e.g. Gertler, Kiyotaki, and Queralto (2012), Roger and Vlcek (2011), Gertler and Karadi (2011), de Walque, Pierrard, and Rouabah (2010), Covas and Fujita (2010), Van den Heuvel (2008), and Goodfriend and McCallum (2007). ${ }^{6}$ The focus on the stable funding requirement, which has not received previous attention, distinguishes our contribution to the theoretical literature. On the other hand, the empirical dimension of this paper links it to the literature on DSGE models of financial intermediation estimated with Bayesian methods on US or Euro-area data, as in e.g. Christiano, Motto, and Rostagno (2014), Jermann and Quadrini (2012) or Gerali, Neri, Sessa, and Signoretti (2010). The consumer-bank interaction in our model is closest to that of Gerali, Neri, Sessa, and Signoretti (2010) who estimate a New Keynesian model with banks on Euro-area data. However, they focus on different macroprudential instruments, namely restrictions on loan-to-value ratios and bank capital holdings. Furthermore, since we fit our model to New Zealand, a very open economy, we introduce international trade in goods and financial assets. The banking sector in our model interacts with a real economy which has much in common with the empirical small open economy (SOE) models of Adolfson et al. (2007) and Bergin (2003). ${ }^{7}$ The openness of the economy adds a unique dimension to our analysis. In line with the case in New Zealand, banks in our model borrow from international financial markets in order to lend at home. For this reason, the current account reflects movements in domestic (net) credit.

The estimated model forms the foundation for our policy analysis where we examine

\footnotetext{
${ }^{5}$ Our results regarding the moderation of losses when monetary policy leans against the wind is along the lines of Quint and Rabanal (2014) and Lambertini, Mendicino, and Punzi (2013). However, they focus on loan-to-value ratios as the prudential instrument, and their metric for evaluating optimal policy is maximisation of households' welfare.

${ }^{6} \mathrm{~A}$ vast literature in finance also studies financial frictions and regulation in smaller scale models, often set in partial equilibrium, solved by non-linear techniques. See Angelini, Neri, and Panetta (2014) for a review of this literature.

${ }^{7}$ Alpanda, Cateau, and Meh (2014) also consider macroprudential policy in the context of a calibrated small open economy model for Canada. While their focus is on loan-to-value ratios and capital requirements, the structure of the real economy is quite similar to ours.
} 
the implications of the stable funding requirement for monetary policy trade-offs. This dimension of the paper links it to a growing DSGE model-based literature focussing on optimal monetary and prudential policy. This literature has hitherto focused on the interactions between monetary policy and loan-to-value ratios or capital requirements, e.g. Quint and Rabanal (2014), Gelain and Ilbas (2014), Angelini, Neri, and Panetta (2014), Lambertini, Mendicino, and Punzi (2013), and Angeloni and Faia (2013). In contrast, we assess how monetary policy trade-offs are altered due to the presence of a stable funding requirement. To this end, we use a monetary policy loss function specified in terms of macroeconomic volatilities akin to those used in Angelini, Neri, and Panetta (2014) and Gelain and Ilbas (2014), and study optimised policy rules that minimise the policy loss function. ${ }^{8}$

Finally, the modelling strategy for the introduction of long-term wholesale funding, which is one of the key target variables of the stable funding requirement, links the paper to the literature on multi-period debt. Woodford (2001) introduced exponentiallydecaying perpetuities in DSGE models as a tractable way of modeling multi-period debt with a single state variable. While this approach is suitable to model fixed-rate financial assets, it can imply a large degree of interest rate risk and associated valuation effects. In our model, multi-period bonds pay a floating rate coupon on the benchmark component to eliminate benchmark interest rate risk, in addition to a fixed-rate spread that cannot be hedged. The introduction of an additional state variable enables us to model the cost structure of bank funding more realistically, implicitly accounting for the fact that modern banks use interest rate swaps to hedge benchmark interest rate risk. ${ }^{9}$

The rest of the paper is set out as follows. In Section 2 we introduce the stable funding requirement in an SOE model for New Zealand and Section 3 describes the estimation results. The implications of the stable funding requirement for monetary policy trade-offs are explored in Section 4. Section 5 concludes.

\footnotetext{
${ }^{8}$ On the other hand, Quint and Rabanal (2014) and Lambertini, Mendicino, and Punzi (2013) use household welfare criteria derived from model-specific utility functions. Angeloni and Faia (2013) employ separate criteria based on welfare as well as volatilities.

${ }^{9} \mathrm{~A}$ different strategy for modelling long-term debt in the context of fixed- and variable-rate mortgages, is considered by Brzoza-Brzezina, Gelain, and Kolasa (2014). See the references therein for the literature studying long-term debt in the housing market.
} 


\section{A Small Open Economy Model with a Stable Fund- ing Requirement}

\section{$2.1 \quad$ Preliminaries}

The model involves two countries, the home country being infinitesimally small when compared to the foreign country. The home country, henceforth referred to as the small open economy (SOE), is populated by a continuum of identical households indexed by $h \in[0,1]$, a continuum of firms indexed by $f \in[0,1]$ and a continuum of banks indexed by $\iota \in[0,1]$. The firms are owned by the households while the banks are owned by the foreign economy, the latter assumption in accordance with the New Zealand experience. In the interests of brevity, this section focusses on the bank and its interface with the rest of the model. Importantly, the design of the real economy is standard and is mostly based on Adolfson et al. (2007). Hence, the associated equilibrium conditions are presented in Section A in the appendix. The foreign country, i.e. the rest of the world, is not impacted by the SOE and is modelled as the canonical 3-equation closed-economy New Keynesian model that determines the dynamics of output, inflation and the nominal interest rate, in the spirit of Justiniano and Preston (2010).

Variables representing nominal quantities are presented in upper case and when they are deflated by the consumption price index $\left(P_{c}\right)$, they are presented in lower case. Net nominal interest rates and net inflation are also presented in lower case. Typically, a variable $z$ in the non-stochastic steady-state is presented as $\bar{z}$. A logarithmic deviation

of the variable relative to its steady-state in period $t$ is represented as $\hat{z}_{t} \equiv \frac{\partial z_{t}}{\bar{z}}=\log \frac{z_{t}}{\bar{z}}$. In addition, we also use the notation $\tilde{z}_{t} \equiv \partial z_{t}$ for net interest rates and inflation in the log-linearised model to indicate percentage deviations in absolute terms. $\mathbb{E}$ and $\Delta$ represent the mathematical operators for conditional expectations and temporal differencing respectively. The typical stochastic shock process $e$ embedded in the model is assigned the law of motion $\log e_{t}=\left(1-\rho_{e}\right) \log \bar{e}+\rho_{e} \log e_{t-1}+\sigma_{e} \eta_{t}$ where $\eta_{t} \sim$ i.i.d. $\mathbb{N}(0,1)$, $\sigma_{e}>0$ and $\rho_{e} \in(0,1)$. 


\subsection{Households}

The generic household $h$ acquires goods for consumption $\left(c_{h}\right)$ and investment $\left(i_{h}\right)$ from the final goods firms at the nominal prices $P_{c}$ and $P_{i}$ respectively. The household's utility function is separable between consumption, adjusted for external habit-formation, and labour $\left(n_{h}\right)$. In contrast to the standard New Keynesian literature, the household holds bank deposits $\left(d_{h}\right)$ that enter the utility function as a third argument, again separably from consumption and labour. The presence of deposits in the household's preferences is motivated by their liquidity value in lowering transaction costs. ${ }^{10}$

The household's budget constraint has the following characteristics. On the income side, households receive a net nominal return of $r^{D}$ on bank deposits while it pays the net nominal rate $r^{L}$ for loans $\left(\ell_{h}\right)$ issued by the bank. Investment in the physical capital stock $\left(k_{h}\right)$ entails investment adjustment costs captured by the convex function $\phi()$. Installed capital is rented out to the firm at the real net rate of $r_{c}^{k}$. Each household is a monopolistic supplier of specialised labour $\left(n_{h}\right)$ and perfectly competitive 'employment agencies' aggregate the specialised labour-varieties from the households into a homogenous labour input $(n)$ using a constant elasticity of substitution (CES) technology and sell it to the firm. The household receives a labour-type specific nominal wage $\left(W_{h}\right)$ from the employment agency. We also introduce nominal wage rigidities by stipulating that it is costly à la Rotemberg (1982) to change wages. Finally, the household also receives nominal dividends $\left(\Omega_{h}\right)$ through its ownership of firms.

The discount factor $\xi$ that the household uses to evaluate expected utility and income, is a decreasing function of average consumption. This device prevents a unit root in the economy's net foreign debt position and allows us to study the dynamics of the model in the neighbourhood of its steady-state. Three structural shocks influence the household's decision problem: $\varepsilon_{\beta}$ that affects the rate of inter-temporal substitution of consumption, $\vartheta_{n, t}$ that is interpreted as the time-varying wage elasticity of labour demand, and $\varepsilon_{i}$ that stimulates capital accumulation.

The household maximises its expected utility in Equation (1) subject to the law of

\footnotetext{
${ }^{10}$ de Walque, Pierrard, and Rouabah (2010) adopt a similar strategy in their DSGE model with a banking sector. Deposits could instead be created by introducing patient and impatient households with the former depositing funds in the bank and the latter demanding loans as in e.g. Gerali et al. (2010). The deposits-in-the-utility function approach provides tractability.
} 
motion for the endogenous discount factor in Equation (2), period budget constraint in Equation (3), capital accumulation constraint in Equation (4), and its labour-variety specific demand constraint in Equation (5) .

$$
\max _{\substack{d_{h, t}, \ell_{h, t}, n_{h, t}, c_{h, t}, k_{h, t}, i_{h, t}, W_{h, t}}} \mathbb{E}_{0} \sum_{t=0}^{\infty} \varepsilon_{\beta, t} \xi_{t}\left[\log \left(c_{h, t}-\gamma_{c} c_{t-1}\right)+\frac{d_{h, t}^{1-\omega_{d}}}{1-\omega_{d}}-\frac{n_{h, t}^{1+\omega_{n}}}{1+\omega_{n}}\right]
$$

subject to

$$
\begin{gathered}
\frac{\xi_{t+1}}{\xi_{t}} \equiv \beta_{t}=\left(1+\beta_{c} \log c_{t}\right)^{-1} \\
c_{h, t}+\frac{P_{i, t}}{P_{c, t}} i_{h, t}+d_{h, t}+\frac{\left(1+r_{t-1}^{L}\right)}{\left(1+\pi_{c, t}\right)} \ell_{h, t-1}=\frac{W_{h, t}}{P_{c, t}} n_{h, t}-\frac{\chi_{w}}{2}\left(\frac{W_{h, t}}{W_{h, t-1}\left(1+\bar{\pi}_{c}\right)}-1\right)^{2} \frac{W_{t}}{P_{c, t}} n_{t} \\
+r_{c, t}^{k} k_{h, t-1}+\frac{\left(1+r_{t-1}^{D}\right)}{\left(1+\pi_{c, t}\right)} d_{h, t-1}+\ell_{h, t}+\frac{\Omega_{h, t}}{P_{c, t}} \\
i_{h, t} \varepsilon_{i, t}\left[1-\phi\left(\frac{i_{h, t}}{i_{h, t-1}}\right)\right]+\left(1-\delta_{k}\right) k_{h, t-1}=k_{h, t} \\
n_{h, t}=n_{t}\left(\frac{W_{h, t}}{W_{t}}\right)^{-\vartheta_{n, t}}
\end{gathered}
$$

where the parameters $\gamma_{c} \in[0,1), \xi_{0}=1, \beta_{c}, \omega_{n}, \omega_{d}>0, \chi_{w} \geqslant 0, \delta_{k} \in[0,1]$, and the cost function $\phi()$ has the properties $\phi(1)=\phi^{\prime}(1)=0$ and $\phi^{\prime \prime}(1)=\phi_{i}>0$. The variable $W$ represents a nominal wage-index for the aggregated unit of labour used by the firms and $1+\pi_{c, t} \equiv P_{c, t} / P_{c, t-1}$ is the gross CPI inflation.

In a symmetric equilibrium, the optimality conditions for loans $(\ell)$ and deposits $(d)$ are respectively:

$$
1=\mathbb{E}_{t} \Lambda_{t, t+1} \frac{\left(1+r_{t}^{L}\right)}{\left(1+\pi_{c, t+1}\right)}
$$

and

$$
\frac{d_{t}^{-\omega_{d}}}{\lambda_{t}}+\mathbb{E}_{t} \Lambda_{t, t+1} \frac{\left(1+r_{t}^{D}\right)}{\left(1+\pi_{c, t+1}\right)}=1
$$

The variable $\lambda$ indicates the marginal utility of consumption and $\Lambda_{t, t+1} \equiv \lambda_{t+1} / \lambda_{t}$ is the stochastic discount factor. Equation (6) is a conventional Euler equation, the only difference being that the return on loans, and not the policy rate determines the rate of time preference. The optimality condition in Equation (7) equates the sum of the current marginal utility gain from deposits, $d_{t}^{-\omega_{d}}$ and the discounted expected utility gain from 
gross deposit returns $\mathbb{E}_{t} \Lambda_{t, t+1}\left(1+r_{t}^{D}\right) /\left(1+\pi_{c, t+1}\right)$ to the cost of foregone consumption. Consequently, in periods when the marginal utility of consumption is high, the household lowers deposit holdings. Observe that the elasticity of deposits to the real return is decreasing in the parameter $\omega_{d}$. From the perspective of bank funding, a high value for $\omega_{d}$ would make deposits very sticky, and hence a more stable source of funding for the bank. ${ }^{11}$ The other first order conditions are standard and are presented in the appendix.

\subsection{Bank}

The representative bank is comprised of three interconnected subdivisions. Firstly, the retail units for deposits and loans are the interface of the bank with the households and they operate in a monopolistically competitive market with sticky nominal interest rates, as in Gerali et al. (2010). The second subdivision, the stable funding unit, combines retail deposits and multi-period bonds into stable funding, which is on-lent to the final subdivision, the aggregate funding unit. The aggregate funding unit combines stable funding and 1-period wholesale funding, subject to a stable funding requirement. The bank is owned by foreign residents, a stylised feature of the model adapted to the New Zealand economy where most of the banks are owned by Australian parent institutions (see e.g. Bollard, 2004). For this reason, bank profits are not rebated to domestic households, but are instead transferred overseas. We start with the description of the aggregate funding unit on which the stable funding requirement, henceforth referred to as the SFR, is imposed.

\subsubsection{Aggregate funding unit and the SFR}

The aggregate funding unit of the representative bank $\iota$ combines stable funding $B^{s f}$ with short-term wholesale funding $B$ to fund a floating-rate loan to households of nominal value $L$. Although set up as a one-period loan, the interest rate structure - and therefore the implicit duration - of the loan reflects the duration of the bank's funding. ${ }^{12}$ The average

\footnotetext{
${ }^{11}$ Later in the estimation results presented in Section 3, we confirm that this is indeed the case for New Zealand as the estimate of $\omega_{d}$ exceeds 100.

${ }^{12}$ The bank on-lends the funds to the retail loan unit at cost. The average rate on many overlapping loans priced at the marginal cost is the same as the rate on a representative loan priced at the bank's average cost of funds. Since the retail units smooth lending rates, changes in the bank's marginal costs are only gradually passed through to lending rates.
} 
nominal interest cost of the stable funding unit is given by $r^{s f}$ while $r$ is the rate paid on one-period wholesale funding. The aggregate funding unit chooses the quantities of stable funding and short-term wholesale funding that maximise the discounted sum of real cash flows subject to the balance sheet constraint:

$$
\max _{b_{\iota, t}^{s f}, b_{\iota, t}} \mathbb{E}_{0} \sum_{t=0}^{\infty} \Lambda_{0, t}^{a f}\left[\begin{array}{c}
b_{\iota, t}^{s f}+b_{\iota, t}+\frac{\left(1+r_{t-1}^{\ell}\right)}{\left(1+\pi_{c, t}\right)} \ell_{\iota, t-1}-\ell_{\iota, t}-\frac{\left(1+r_{t-1}^{s f}\right)}{\left(1+\pi_{c, t}\right)} b_{\iota, t-1}^{s f}-\frac{\left(1+r_{t-1}\right)}{\left(1+\pi_{c, t}\right)} b_{\iota, t-1} \\
-\frac{b_{t-1}^{s f}}{\left(1+\pi_{c, t}\right)} \Upsilon\left(\frac{b_{\iota, t-1}^{s f}}{\ell_{\iota, t-1}}\right)
\end{array}\right]
$$

subject to

$$
\ell_{\iota, t}=b_{\iota, t}^{s f}+b_{\iota, t}
$$

where $\Lambda^{a f}$ is the discount factor of the aggregate funding unit. ${ }^{13}$ The SFR enters the cash-flow problem through an adjustment cost function. The bank incurs a cost $\Upsilon($ ) when the stable funding to loans ratio deviates from the requirement of $\nu^{s f r}$. In particular:

$$
\Upsilon\left(\frac{b_{\iota, t}^{s f}}{\ell_{\iota, t}}\right)=\gamma_{0}+\gamma_{1}\left(\frac{b_{\iota, t}^{s f}}{\ell_{\iota, t}}-\nu_{t}^{s f r}\right)+\frac{\gamma_{2}}{2}\left(\frac{b_{\iota, t}^{s f}}{\ell_{\iota, t}}-\nu_{t}^{s f r}\right)^{2}
$$

The cost function $\Upsilon($ ) has a linear as well as quadratic component to allow for a nonzero steady-state value for the first derivative of the cost, so that there exist wedges between the interest rates in the long run, as observed in the sample means in the data. ${ }^{14}$ While it is natural to think of the stable funding ratio as being a result of explicit, external regulation, it may also reflect banks' internal risk management or pressure from creditors. In the absence of the adjustment penalty, the bank would seek to fund only from short-term markets.

The optimality condition for short-term wholesale funding $(b)$ defines the spread between the nominal internal loan rate $r^{\ell}$ received from the lending unit and the nominal benchmark rate $r$ paid for short-term wholesale funding:

$$
r_{t}^{\ell}-r_{t}=-\left(\frac{b_{t}^{s f}}{\ell_{t}}\right)^{2} \Upsilon^{\prime}\left(\frac{b_{t}^{s f}}{\ell_{t}}\right)
$$

\footnotetext{
${ }^{13}$ We additionally assume the existence of 1-period foreign currency bonds which are in zero netsupply, in order to obtain the no-arbirtrage condition which equates the expected depreciation of the home currency to the international interest rate differential.

${ }^{14}$ In Section 3 on the empirical implementation of the model, we set $\gamma_{0}$ to zero while $\gamma_{1}$ is pinned down by the steady-state restrictions. $\gamma_{2}$ is estimated.
} 
The left hand side of Equation (11) is the additional profit from an additional unit of lending funded with short-term wholesale borrowing, and the right hand side is the cost of deviating from the SFR. Combining the above condition with the optimality condition for stable funding (not exhibited) yields the spread between the nominal rate $r^{s f}$ paid to the stable funding unit and the cost of short-term wholesale funding:

$$
r_{t}^{s f}-r_{t}=-\frac{b_{t}^{s f}}{\ell_{t}} \Upsilon^{\prime}\left(\frac{b_{t}^{s f}}{\ell_{t}}\right) .
$$

Here, the benefit of substituting one unit of cheaper short-term wholesale funding for one unit of stable funding, $r^{s f}-r$ is equated with the cost of deviating from the SFR. Combining the two equilibrium conditions above, we can express the internal loan rate as a weighted average of the short-term wholesale rate and the average rate paid for stable funding, with the weights determined by the stable funding to loans ratio:

$$
r_{t}^{\ell}=\left(\frac{b_{t}^{s f}}{\ell_{t}}\right) r_{t}^{s f}+\left(1-\frac{b_{t}^{s f}}{\ell_{t}}\right) r_{t} .
$$

In Section 4.2, we demonstrate that this relationship is crucial to determining the infuence of the prudential requiment set on the stable funding to loans ratio, on the cost of loanable funds, credit and the macroeconomy.

\subsubsection{Stable funding unit}

The SFR stipulates that the bank funds a share of its assets through either deposits or multi-period bonds. While the stickiness of deposit demand makes deposits a stable source of bank funding, multi-period bonds are stable in the sense that only a fixed fraction of bonds mature in each period. Multi-period bonds enter the optimisation

problem of the stable funding unit of the bank that produces stable funding $B^{s f}$ by combining its stock of unmatured multi-period bonds $S^{m}$ available in the current period with one-period retail deposits. The stable funding unit then lends the funds to the aggregate funding unit at the net average cost of stable funding, $r^{s f}$. In CPI-deflated terms, the balance sheet constraint of the stable funding unit is given by:

$$
d_{t}+s_{t}^{m}=b_{t}^{s f}
$$


Modelling multi-period debt and interest Our strategy to model long-term debt is based on that of Woodford (2001) who incorporates a perpetuity-structure into an otherwise conventional DSGE model to study fixed-rate long-term government debt. ${ }^{15}$ However, long-term debt with fixed returns, would expose the bank to a large degree of interest-rate risk, unless all the bank's assets and liabilities have matched duration. To eliminate benchmark interest-rate risk, we augment Woodford's framework by including two distinct components into the return on long-term bonds: a floating rate benchmark and a fixed spread. In every period, new bonds $B^{m}$ of fixed duration $d^{m}$ are sold to non-residents at the net floating benchmark rate $(r)$ and an additional funding spread that is fixed at the time of issuance. ${ }^{16}$ The bond repayments are split into two parts: firstly the predetermined principal repayments and the spread, and secondly, floating rate coupon payments. As in Woodford (2001), the principal is repaid in an infinite number of installments decaying geometrically at the rate $\delta^{m} \in[0,1)$, starting from the next period. The floating rate coupon and fixed spread components are paid on the decaying stock of outstanding bonds. The degree of funding liquidity risk is determined by the maturing principal which is a function of the rate of decay $\delta^{m}$. If $Q_{t}$ is the fixed payment, related to principal and the fixed spread, on a bond raised in period $t$, then total repayments are scheduled as follows:

$$
\begin{array}{cc}
\text { In period } t+1: & \left(Q_{t}+r_{t}\right) B_{t}^{m} \\
\text { In period } t+2: & \delta^{m}\left(Q_{t}+r_{t+1}\right) B_{t}^{m} \\
\text { In period } t+3: & \left(\delta^{m}\right)^{2}\left(Q_{t}+r_{t+2}\right) B_{t}^{m} \\
\cdot & \cdot \\
\cdot & \cdot \\
\text { In period } t+z: & \left(\delta^{m}\right)^{z-1}\left(Q_{t}+r_{t+z-1}\right) B_{t}^{m}
\end{array}
$$

Note that $Q_{t} B_{t}^{m}$ covers the principal repayment $\left(1-\delta^{m}\right) B_{t}^{m}$ and the fixed spread $\tau_{t}^{m} B_{t}^{m}$ component of interest payments, so that $Q_{t}=1-\delta^{m}+\tau_{t}^{m} \cdot{ }^{17}$ The sum of repayments of

\footnotetext{
${ }^{15}$ Benes and Lees (2010) discuss Woodford's perpetuity set-up in detail and we closely follow their notation.

${ }^{16}$ Fixed-coupon payments (or receipts) are assumed to be swapped to floating-coupon payments (or receipts) at the one-period benchmark rate combined with a fixed spread.

${ }^{17}$ The duration $d^{m}$ of the funding is the expected present value $(P V)$ of repayments discounted at the rate of return on stable funding. Defining $R^{s f}=1+r^{s f}, \mathbb{E}_{t} P V_{t+z}=$ $\left(\delta^{m}\right)^{z-1}\left(Q_{t}+\mathbb{E}_{t} r_{t+z}\right)\left(R_{t}^{s f} \mathbb{E}_{t} R_{t+1}^{s f} \ldots \mathbb{E}_{t} R_{t+z-1}^{s f}\right)^{-1} \quad$ weighted by the time-to-maturity: $d^{m}=$ $\sum_{z=1}^{\infty} z \mathbb{E}_{t} P V_{t+z} / \sum_{z=1}^{\infty} \mathbb{E}_{t} P V_{t+z}$. In the non-stochastic steady-state, $\bar{d}^{m}=\bar{R}^{s f} /\left(\bar{R}^{s f}-\delta^{m}\right)$.
} 
the principal in addition to the fixed spread on all past wholesale funding due in period $t$ (excluding floating interest payments) is

$$
J_{t-1}=\sum_{z=1}^{\infty}\left(\delta^{m}\right)^{z-1}\left(Q_{t-z} B_{t-z}^{m}\right)
$$

which can expressed in recursive form as:

$$
J_{t}=\delta^{m} J_{t-1}+Q_{t} B_{t}^{m}
$$

The book value of the principal declines at the rate $\delta^{m}$ so that the law of motion of the stock of unmatured bonds $S^{m}$ is given by:

$$
S_{t}^{m}=\delta^{m} S_{t-1}^{m}+B_{t}^{m}
$$

The spread $\tau^{m}$ on the cost of multi-period bonds is modelled as an exogenous $\operatorname{AR}(1)$ process. The exogeneity of the funding spread is well suited to the case of banks from the SOE accessing external wholesale bank funding markets. Such spreads may be driven by aggregate risk, rather than idiosyncratic bank-specific risk (Acharya and Skeie, 2011).

Optimal deposit and bonds funding In period $t$, the stable funding unit receives gross interest returns on funds lent to the aggregate funding unit in the previous period, issues new bonds $B_{t}^{m}$ and raises deposits $D_{t}$. It repays the deposit unit with interest, repays maturing principal and interest on outstanding bonds $J_{t-1}+r_{t-1} S_{t-1}^{m}$ and is subject to adjustment costs if it expands funding from less-liquid long-term markets. We present the optimisation problem of the representative stable funding unit in terms of CPI-deflated quantities:

$$
\max _{\substack{b_{\iota, t}^{s f}, d_{\iota, t}, b_{\iota, t}^{m} \\
j_{\iota, t}, s_{\iota, t}^{m}}} \mathbb{E}_{0} \sum_{t=0}^{\infty} \Lambda_{0, t}^{s f}\left[\begin{array}{c}
b_{\iota, t}^{m}+d_{\iota, t}+\frac{\left(1+r_{t-1}^{s f}\right)}{\left(1+\pi_{c, t}\right)} b_{\iota, t-1}^{s f}-b_{\iota, t}^{s f}-\frac{j_{\iota, t-1}}{\left(1+\pi_{c, t}\right)}-r_{t-1} \frac{s_{\iota, t-1}^{m}}{\left(1+\pi_{c, t}\right)} \\
-\frac{\left(1+r_{t-1}^{d}\right)}{\left(1+\pi_{c, t}\right)} d_{\iota, t-1}-\frac{\kappa^{m}}{2}\left(\frac{b_{\iota, t}^{m}}{b_{\iota, t-1}^{m}}-1\right)^{2} b_{t}^{m}
\end{array}\right]
$$


subject to

$$
\begin{gathered}
j_{\iota, t}=\delta^{m} \frac{j_{\iota, t-1}}{\left(1+\pi_{c, t}\right)}+Q_{t} b_{\iota, t}^{m}, \\
\text { and } s_{\iota, t}^{m}=\delta^{m} \frac{s_{\iota, t-1}^{m}}{\left(1+\pi_{c, t}\right)}+b_{\iota, t}^{m},
\end{gathered}
$$

where $\Lambda^{s f}$ is the discount factor of the stable funding unit. The law of motion constraints in Equations (19) and (20) are associated with the Lagrange multipliers $\Psi$ and $\Phi$ respectively. The term involving $\kappa^{m} \geqslant 0$ is a quadratic adjustment cost associated with changing the stock of nominal bonds raised. Implicitly, such a cost may represent higher marketing costs or commitment issues related to debt repayment. Since the bank borrows in home currency, such costs may relate not only to net issuance in foreign debt markets, but also to markets for hedging foreign currency exposure. In effect, this feature captures a relative liquidity effect: prices respond to volumes by more in less-liquid long-term markets than in short-term markets. If outstanding bonds increase rapidly, i.e. new issuance exceeds maturing debt, then the bank sells the bonds at a discount.

In a symmetric equilibrium, the first order conditions for stable funding $\left(b^{s f}\right)$, deposits $(d)$, multi-period bonds $\left(b^{m}\right)$, repayments on past borrowing $(j)$, and the stock of bonds $\left(s^{m}\right)$ are respectively:

$$
\begin{gathered}
1=\mathbb{E}_{t} \Lambda_{t, t+1}^{s f} \frac{\left(1+r_{t}^{s f}\right)}{\left(1+\pi_{c, t+1}\right)}, \\
1=\mathbb{E}_{t} \Lambda_{t, t+1}^{s f} \frac{\left(1+r_{t}^{d}\right)}{\left(1+\pi_{c, t+1}\right)}, \\
1=\Psi_{t} Q_{t}+\Phi_{t}+\frac{b_{t}^{m}}{b_{t-1}^{m}} \kappa^{m}\left(\frac{b_{t}^{m}}{b_{t-1}^{m}}-1\right)-\mathbb{E}_{t} \Lambda_{t, t+1}^{s f}\left(\frac{b_{t+1}^{m}}{b_{t}^{m}}\right)^{2} \kappa^{m}\left(\frac{b_{t+1}^{m}}{b_{t}^{m}}-1\right), \\
\Psi_{t}=\mathbb{E}_{t} \frac{\Lambda_{t, t+1}^{s f}}{\left(1+\pi_{c, t+1}\right)}\left(1+\delta^{m} \Psi_{t+1}\right), \\
\text { and } \Phi_{t}=\mathbb{E}_{t} \frac{\Lambda_{t, t+1}^{s f}}{\left(1+\pi_{c, t+1}\right)}\left(r_{t}+\delta^{m} \Phi_{t+1}\right) .
\end{gathered}
$$

Equations (21) and (22) are standard asset pricing conditions which equalise the returns for stable funding $r^{s f}$ and the one-period retail deposits $r^{d}$. The optimality condition for multi-period bonds in Equation (23) associates the price of a new bond to the sum of the present value of expected future fixed payments $\Psi Q$ and the present value of expected 
floating rate payments, $\Phi$. In addition, observe that in the presence of positive adjustment costs $\left(\kappa^{m}>0\right)$, increasing bond holdings decreases the proceeds from issuing the bond in the current period. However, in the ensuing period the costs are lower, augmenting the value of the bond. The first order condition for fixed payments in Equation (24) pins down the dynamics of the associated marginal profit. A unit decrease in $j$ increases the profit of the bank in the current period by $\Psi_{t}$ while reducing the future profit by raising repayments in the next period by a factor of $1+\delta^{m} \Psi_{t+1}$. In present value terms, the two coincide in equilibrium. Analogously, the optimality condition for unmatured bonds $s^{m}$ in Equation (25) determines the path of marginal profits $\Phi$ from making floating rate repayments.

Combining new bonds with previously contracted bonds Deposits and new bonds are raised at the marginal cost of stable funding and unmatured bonds are paid at the benchmark rate, in addition to the previously contracted spreads. The proceeds of bonds are lent to the aggregate funding unit at the average cost of stable funding:

$$
\frac{\left(1+r_{t-1}^{s f}\right)}{\left(1+\pi_{c, t}\right)} b_{t-1}^{s f}=\frac{\left(1+r_{t-1}^{d}\right)}{\left(1+\pi_{c, t}\right)} d_{t-1}+\frac{j_{t-1}}{\left(1+\pi_{c, t}\right)}+\frac{\left(r_{t-1}+\delta^{m}\right)}{\left(1+\pi_{c, t}\right)} s_{t-1}^{m}+\frac{\kappa^{m}}{2}\left(\frac{b_{t}^{m}}{b_{t-1}^{m}}-1\right)^{2} b_{t}^{m}
$$

\subsubsection{Retail banking units}

Following Gerali et al. (2010), we model market power in retail loan and deposit banking markets using a Dixit-Stiglitz framework. We assume that (real) units of loans and deposits bought by households are composite CES baskets of differentiated financial products, with elasticities of substitution given by $\vartheta^{L}$ and $\vartheta^{D}$ respectively. Each household seeks to minimise repayments over the range of individual contracts. Aggregating over symmetric households, the aggregate loan and deposit demand faced by the bank are given by:

$$
\ell_{\iota, t}=\ell_{t}\left(\frac{r_{\iota, t}^{L}}{r_{t}^{L}}\right)^{-\vartheta_{t}^{L}} \text { and } d_{\iota, t}=d_{t}\left(\frac{r_{\iota, t}^{D}}{r_{t}^{D}}\right)^{-\vartheta_{t}^{D}}
$$

The retail lending unit receives funds from the aggregate funding unit and lends the funds to households. In adjusting the nominal loan rate, it incurs quadratic adjustment costs, increasing in $\kappa^{L} \geqslant 0$. The lending unit of the bank $\iota$ maximises expected profits subject 
to the demand function given above:

$$
\max _{r_{\iota, t}^{L}} \mathbb{E}_{0} \sum_{t=0}^{\infty} \Lambda_{0, t}^{L}\left[\left(r_{\iota, t-1}^{L}-r_{t-1}^{\ell}\right) \ell_{\iota, t-1}-\frac{\kappa^{L}}{2}\left(\frac{r_{\iota, t}^{L}}{r_{\iota, t-1}^{L}}-1\right)^{2} r_{t}^{L} \ell_{t}\right] \text { subject to } \ell_{\iota, t}=\left(\frac{r_{\iota, t}^{L}}{r_{t}^{L}}\right)^{-\vartheta_{t}^{L}} \ell_{t},
$$

where $\Lambda^{L}$ is the associated discount factor. In a symmetric equilibrium, the first order condition is given by:

$$
\frac{r_{t}^{L}}{r_{t-1}^{L}} \kappa^{L}\left(\frac{r_{t}^{L}}{r_{t-1}^{L}}-1\right)=\mathbb{E}_{t} \Lambda_{t, t+1}^{L}\left[\left(\frac{r_{t+1}^{L}}{r_{t}^{L}}\right)^{2} \frac{\ell_{t+1}}{\ell_{t}} \kappa^{L}\left(\frac{r_{t+1}^{L}}{r_{t}^{L}}-1\right)-\vartheta_{t}^{L}\left(\frac{r_{t}^{L}-r_{t}^{\ell}}{r_{t}^{L}}\right)+1\right] .
$$

The lending rate exhibits Phillips-curve type dynamics, changing only gradually in response to the change in the cost of funds $r^{\ell}$. The retail deposit unit faces an optimisation problem similar to that of the lending unit and sets the wedge between the deposit rate $r^{D}$ and the internal value $r^{d}$. The corresponding optimality condition is:

$$
\frac{r_{t}^{D}}{r_{t-1}^{D}} \kappa^{D}\left(\frac{r_{t}^{D}}{r_{t-1}^{D}}-1\right)=\mathbb{E}_{t} \Lambda_{t, t+1}^{D}\left[\left(\frac{r_{t+1}^{D}}{r_{t}^{D}}\right)^{2} \frac{d_{t+1}}{d_{t}} \kappa^{D}\left(\frac{r_{t+1}^{L}}{r_{t}^{L}}-1\right)-\vartheta_{t}^{D}\left(\frac{r_{t}^{d}-r_{t}^{D}}{r_{t}^{d}}\right)+1\right]
$$

where $\Lambda^{D}$ is the discount factor of the retail deposit unit and the adjustment cost parameter $\kappa^{D} \geqslant 0$. In the steady-state when adjustment costs are absent, optimality requires that that the retail deposit rate markup over the internal value is less than unity while the corresponding retail loan rate markup exceeds unity. Outside the steady-state, the markups are time-varying since they are influenced by nominal rate stickiness as well as by structural shocks to the demand elasticities $\vartheta^{D}$ and $\vartheta^{L}$.

\subsection{Firms}

Monopolistic competition and nominal rigidities in price-setting characterise the three categories of intermediate goods firms. The first group of firms produce goods using capital and labour inputs in a Cobb-Douglas combination to sell domestically. The second group involves exporting firms that buy the domestic good and sell it in the world market, while the third category comprises importing firms that procure the foreign good in order to sell at home. Perfectly competitive aggregator firms combine the imported and domestic goods using CES technologies to sell to the household for consumption and 
investment.

\subsection{Balance of payments}

Aggregating the constraints of the household, the firms and the bank, we arrive at the balance of payments (in nominal terms) of the SOE:

$$
\begin{aligned}
\frac{P_{x, t}}{n e r_{t}} y_{x, t}-\frac{P_{t}^{*}}{n e r_{t}}\left(c_{m, t}+i_{m, t}\right)+P_{c, t} b_{t}^{m}+P_{c, t} b_{t}= & P_{c, t-1} j_{t-1}+r_{t-1} P_{c, t-1} s_{t-1}^{m} \\
& +\left(1+r_{t-1}\right) P_{c, t-1} b_{t-1}+\Omega_{t}^{B}+A C_{t}^{B} .
\end{aligned}
$$

The first two terms reflect the trade balance: the excess of the revenue from exporting volumes $\left(y_{x}\right)$ at the price $\left(P_{x}\right)$ over the expenditure on consumption imports $\left(c_{m}\right)$ and investment imports $\left(i_{m}\right)$ at the acquisition cost $\left(P^{*}\right)$ of the foreign good. The next two terms represent the country's net external debt: the nominal value of outstanding bills and bonds borrowed from non-residents. The right hand side reflects the previous period's net external debt in addition to payments that accrue to the foreign economy including interest and principal repayments, bank profits $\left(\Omega^{B}\right)$ paid to the non-resident owners, and quadratic adjustment costs $\left(A C^{B}\right)$.

\subsection{Policy}

The model is closed by specifying monetary and prudential policy. The monetary policy authority sets the benchmark nominal interest rate according to a Taylor-type rule. The nominal interest rate is influenced by past interest rates and also responds to the expected CPI inflation rate. $r_{R} \in[0,1)$ measures the inertia in the policy rate and $r_{\pi}>1$ is the elasticity of the policy rate to inflation while $r_{y}$ governs the reaction to output:

$$
\frac{1+r_{t}}{1+\bar{r}}=\left(\frac{1+r_{t-1}}{1+\bar{r}}\right)^{r_{R}}\left(\frac{1+\mathbb{E}_{t} \pi_{c, t+1}}{1+\bar{\pi}_{c}}\right)^{\left(1-r_{R}\right) r_{\pi}}\left(\frac{y_{t}}{\bar{y}}\right)^{\left(1-r_{R}\right) r_{y}} \exp \varepsilon_{m p, t} .
$$

The variable $\varepsilon_{m p}$ represents the unsystematic, exogenous component in the conduct of monetary policy and is modelled as an AR(1) process. Finally, the prudential policy sets the SFR according to a rule. The SFR is influenced by past SFR settings and also may 
respond to the funding spread. ${ }^{18}$ The parameter $\rho_{s f r} \in[0,1)$ measures the inertia in the SFR setting and $\nu_{\tau}$ is the elasticity of the SFR to the funding spread, while $\sigma_{s f r} \eta_{s f r, t}$ may be interpreted as the unsystematic, exogenous component of variation in the SFR:

$$
\nu_{t}^{s f r}=\left(\nu_{t-1}^{s f r}\right)^{\rho_{s f r}}\left(\tau_{t}^{m}\right)^{\left(1-\rho_{s f r}\right) \nu_{\tau}} \exp \left(\sigma_{s f r} \eta_{s f r, t}\right)
$$

\section{Estimation}

Several papers in the literature have presented DSGE models estimated on New Zealand data (see e.g. Kamber et al., 2015, Justiniano and Preston, 2010, Kam et al., 2009 and Lubik and Schorfheide, 2007). Since these models exclude an explicit role for financial intermediation, we will now take the SOE model to the data in order to pin down the financial parameters and shocks that are important for the policy analysis that follows in Section 4. The model estimation as well as the ensuing optimal policy analysis in Section 4, are implemented in the Matlab-based toolbox Dynare Version 4.4 .2 (see Adjemian et al., 2011).

\subsection{Data and methodology}

The SOE model is estimated employing 15 quarterly macroeconomic time series for New Zealand. We use per capita growth rates of output, consumption, investment, deposits, loans and bond holdings. The remaining data series are: CPI inflation, export price inflation, import price inflation, real wage inflation, the 90-day bank bill rate (which closely tracks the policy rate), retail deposit rate, retail loan rates, the 5-year funding spread, and finally, the observed stable funding ratio.

The observed measure of the stable funding ratio we use is the ratio of the sum of retail deposits and wholesale funding with a residual maturity greater than a year, to total funding. We abstract from bank capital and from liquid assets which on average account for roughly $10 \%$ of assets in New Zealand. Since these components of the balance sheet are not explicitly modelled in our framework, the calibration of the model SFR is adjusted to account for this omission.

\footnotetext{
${ }^{18}$ We also estimated variants of the model where the spread systematically responds to output. However, the coefficient was close to zero and statistically insignificant.
} 
Although the Reserve Bank of New Zealand only imposed the stable funding requirement in April 2010, New Zealand banks have previously used stable funding due to internal risk management strategy or implicit requirements imposed by creditors and rating agencies. Hence, the starting date for this time-series, predates the official requirement imposed in 2010. The availability of data for the spread limits the start-date of the sample to 1998.Q4 and the dataset ends in 2014.Q3. Table 1 presents a more detailed description of the data.

We apply the Bayesian estimation methodology discussed by An and Schorfheide (2007). The Bayesian approach combines prior knowledge about structural parameters with information in the data as embodied by the likelihood function. The combination of the prior and the likelihood function yields posterior distributions for the structural parameters, which are then used for inference. The appendix provides further technical details on the estimation methodology in Section B.

\subsection{Priors}

An overview of the priors used for the structural parameters are documented in Table 2 and those for the shocks are detailed in Table 3. Since we have no previous estimates for the banking sector parameters for New Zealand, the priors that we use are very diffuse. The retail deposit and loan adjustment parameters $\left(\kappa^{D}, \kappa^{L}\right)$ are given Normal priors centered at 5 which span the range of estimates of Gerali et al. (2010) for the Euro-area. The curvature parameter $\left(\gamma_{2}\right)$ for the stable funding adjustment cost function is given a similar prior as the retail interest rate cost parameters. The interest rate elasticity of the demand for deposits $\left(\omega_{d}\right)$ is given a Normal prior centred at 50 but is allowed to cover a wide range of values with the standard deviation being set very high at 200 . The Normal priors that we use for the bond adjustment cost parameter $\left(\kappa^{m}\right)$ and the elasticity of the stable funding requirement to the spread $\left(\nu_{\tau}\right)$ are given low means at 0.1 and 0 respectively, along with a unit variance. The investment adjustment cost parameter $\left(\phi_{i}\right)$ is given a Normal prior centered at 5 , which spans the region covered by similar cost parameters estimated in the literature. ${ }^{19}$ The cost and indexation parameters for price and wage adjustment are given Normal priors centered at the posterior estimates

\footnotetext{
${ }^{19}$ Smets and Wouters (2007) find an estimate of 5.7 for the United States and Adolfson et al. (2007) estimate the parameter to be 7.7 for the Euro-area.
} 
of Kamber et al. (2015). Other real-economy parameters such as those pertaining to the monetary policy rule, habit persistence and shock persistence and volatility are given priors similar to those of Kamber et al. (2015).

A subset of the structural parameters are given dogmatic priors at fixed values. Most of these parameters are crucial for the model's steady-state while others are fixed as there is insufficient information in the dataset to achieve identification. The share of capital in production is fixed at 0.30 and the depreciation of the capital stock is given a value of 0.025 . The price and wage markups are set at 1.1. We rely on the estimates for the New Zealand economy presented in Kamber et al. (2015) to fix the inverse of the Frisch elasticity of labour at 1.34 and the import- and export-demand price elasticities at 0.52 and 0.81 respectively. These values are close to the standard parameterisations used in the literature. We rely on New Zealand national accounts data to calibrate the longrun share of exogenous (government) spending in output at 0.14 and the import-shares of consumption and investment and the export-to-output ratio at $0.20,0.68$ and 0.31 respectively. The foreign-economy parameters are given the same values as those of the domestic-economy analogues.

Following Gerali et al. (2010), the parameters that pertain to the banking sector are calibrated to match observed interest rates, spreads and funding shares. In our case, they are chosen to match properties of the New Zealand banking system. The steadystate loan markup is set at 1.4 to match the average 200 basis point spread between the effective mortgage rate and the model-implied average cost of funds. Similarly, the deposit markdown is calibrated at 0.76 to match the average 75 basis point spread between the model-implied average cost of stable funding and the 6 -month retail deposit rate. The steady-state bond spread is set at 0.0038 , equivalent to 150 basis points per year. The steady-state ratio of deposits to (annual) output is set at 0.8 . The ratio of net external debt to (annual) output is 0.7 . The average duration of new bonds is set at 5 years to match the average maturity of New Zealand bank wholesale funding with a residual maturity of more than a year. The steady-state SFR is set at 0.54 , to match the sample average ratio of the sum of deposits and bonds to loans. 


\subsection{Posteriors}

Tables 2 and 3 also present the moments of the marginal posterior distributions of the estimated parameters. The estimates of the parameters related to the banking sector are of particular interest as we have no previous empirical evidence of their magnitudes. The parameter $\gamma_{2}$ that governs the curvature of the SFR penalty function is estimated at 5.02 which is quite close to the prior mean that is imposed. The data is more informative about the other financial parameters. The preference parameter $\omega_{d}$ that influences the volatility of deposit demand is very high at 112 , implying that the deposits are extremely sticky. The retail loan and deposit rate adjustment cost parameters are estimated at about 9.5 and 7.3 respectively which are not far from the estimates of Gerali et al. (2010) about 10 and 4 for the Euro-area. The bond adjustment cost parameter $\kappa^{m}$ is statistically insignificant as is the response $\left(v_{\tau}\right)$ of the SFR to the funding spread. The investment adjustment cost parameter is estimated at about 4.8 which is similar to the value obtained by Smets and Wouters (2007) for the United States. The remaining realeconomy parameters pertaining to nominal rigidities and the monetary policy reaction function are in the ballpark of the corresponding estimates for New Zealand presented in Kamber et al. (2015). ${ }^{20}$

The transmission channels of three structural disturbances - the funding spread shock, monetary policy shock and the SFR shock - are crucial for the policy analysis that we pursue in the remainder of the paper. Since the interaction between the monetary and macroprudential instruments are closely linked to the business cycle dynamics triggered by these disturbances, we defer the discussion of the estimated impulse responses to the next section. There we focus on the dynamics from the baseline estimation results and how the transmission channels are affected when we alter model features. A discussion of the dynamics triggered by the wider array of shocks that we have employed in the estimation, is available on request.

\footnotetext{
${ }^{20}$ We evaluate the overall empirical fit of the model in Section B. The volatilities and persistence observed in the data are generally in line with the predictions of the model.
} 


\section{The SFR and Monetary Policy Trade-offs}

We now consider the interaction between the SFR and monetary policy. First, in Section 4.1, we describe the monetary policy loss functions that form the basis for the analysis to follow. We then examine the design of optimal monetary and cyclical SFR policy, from the perspective of the monetary policy loss function, within the class of the empirical rules defined by Equations (32) and (33). For each of these exercises, we set all the non-policy structural parameters at the posterior mode. In Section 4.2, we restrict our attention to the effect of changes in the steady-state SFR level on monetary policy trade-offs. In Section 4.3, we ask whether extending the monetary policy rule with financial variables can improve outcomes. Finally, in Section 4.4, we examine if varying the SFR instrument in response to financial variables can improve monetary policy trade-offs.

\subsection{Monetary policy loss functions}

A crucial ingredient in our policy analysis is the specification of the loss function of the monetary policy authority. Our choice of the loss function is motivated by two concerns. Firstly, the functional form of the loss function should be consistent with the Policy Targets Agreement (PTA 2012) between the Governor of the RBNZ and the Minister of Finance, which states the goals of the RBNZ as:

The policy target shall be to keep future CPI inflation outcomes [near target] on average over the medium term... In pursuing its price stability objective, the Bank shall ... have regard to the efficiency and soundness of the financial system, ... and seek to avoid unnecessary instability in output, interest rates and the exchange rate.

Secondly, we need to ensure that the optimal policy parameters delivered by the selected loss function, given the model, are empirically plausible.

We consider four specifications of the loss functions: three from the literature, and one that is specific to the estimated model. We first consider two 'standard' loss functions 
used in Justiniano and Preston (2010):

$$
\begin{aligned}
& \mathcal{L}_{t}=\tilde{\pi}_{t}^{2}+\tilde{r}_{t}^{2} \\
& \mathcal{L}_{t}=\tilde{\pi}_{t}^{2}+0.5 \hat{y}_{t}^{2}+\tilde{r}_{t}^{2}
\end{aligned}
$$

Loss functions such as these above have also been used in the recent macroprudential literature, e.g. Angelini, Neri, and Panetta (2014) and Gelain and Ilbas (2014). The third loss function we consider is from Kam, Lees, and Liu (2009) who estimate a monetary policy loss function for New Zealand of the form:

$$
\mathcal{L}_{t}=\tilde{\pi}_{t}^{2}+0.41 \hat{y}_{t}^{2}+0.61 \Delta \tilde{r}_{t}^{2}+0.005 \widehat{r e r}_{t}^{2}
$$

where $r e r$ is the CPI-based real exchange rate.

None of these loss functions from the literature deliver optimal monetary policy parameters that are in the neighbourhood of the estimated rule. Therefore we also consider a loss function which is more consistent with the estimated model. In particular, we assume that the estimated policy rule is optimal, given the model and given central bank preferences, and then use the estimated reaction function to make inferences about the loss function parameters. ${ }^{21}$ As a first step, we choose a generalised form of the loss function:

$$
\mathcal{L}_{t}=\tilde{\pi}_{t}^{2}+\Theta_{\mathbb{X}} \cdot \mathbb{X}_{t}^{2}
$$

where the welfare loss $(\mathcal{L})$ is increasing in deviations from the primary inflation target, and in deviations in one or more candidate variables in the vector $\mathbb{X}$. $\mathbb{X}$ represents a subset of the following variables: the level or change in the output-gap, the policy interest rate, and the real exchange rate, all of which are associated with the subsidiary objectives of the Reserve Bank stated in the PTA (2012). $\Theta_{\mathbb{X}}$ is a vector of the weights attached to the candidate variables in the loss function. Recall that the monetary policy reaction

\footnotetext{
${ }^{21}$ There are multiple ways to specifying an appropriate welfare loss function and a more detailed treatment of this issue is beyond the scope of our paper. Several studies recover loss function parameters from observed policy behaviour, conditional on the model and on the assumption that observed central bank behaviour is optimal. In the DSGE literature, Kam, Lees, and Liu (2009) back out loss function parameters for Australia, Canada and New Zealand using a small open economy New Keynesian model based on Gali and Monacelli (2005), while Dennis (2006) and Ilbas (2012) implement a similar exercise for the United States.
} 
function that we have specified in the model is of the (log-linear) form:

$$
\tilde{r}_{t}=r_{R} \tilde{r}_{t-1}+\left(1-r_{R}\right)\left(r_{\pi} \mathbb{E}_{t} \tilde{\pi}_{c, t+1}+r_{y} \hat{y}_{t}\right)
$$

For each combination of candidate variables in the loss function, we solve for the optimal

policy rule coefficients $\left\{r_{R}^{o p t}, r_{\pi}^{o p t}, r_{y}^{o p t}\right\}$. The results are reported in Table 4 . For the simplest possible loss function that includes only the primary inflation target $\left(\Theta_{\mathbb{X}}=0\right)$, optimal policy coefficients are far from their estimated analogues; the optimal inflation response is almost 90 compared to about 2 in the estimated monetary policy rule.

We add the additional candidate loss function variables one at a time, and calculate the optimal policy rule coefficients for a grid of loss function weights, $\Theta_{\mathbb{X}}$. For each functional specification, we report the weights that yield optimal policy rule parameters closest to the estimated rule. This final step is in line with our second objective to ensure that the optimal policy rule is empirically plausible. None of the one- or two-variable loss function specifications considered (not exhibited in Table 4), deliver optimal policy coefficients that span the estimated rule. The loss function that delivers optimal policy coefficients closest to the estimated rule, includes the volatility of inflation, the interest rate, and changes in the real exchange rate:

$$
\mathcal{L}_{t}=\tilde{\pi}_{t}^{2}+1.74 \tilde{r}_{t}^{2}+0.55 \Delta \widehat{\operatorname{rer}}_{t}^{2}
$$

The optimal policy coefficients for this specification of the loss function are given by $r_{R}^{o p t}=0.86, r_{\pi}^{\text {opt }}=1.95$ and $r_{y}^{\text {opt }}=0.035$. With this model-specific loss function, we can carry out policy experiments in the neighborhood of the estimated policy rule.

\subsection{The steady-state SFR level and monetary policy trade-offs}

The Reserve Bank of New Zealand introduced the core funding ratio, the analogue of the model SFR, in April 2010 and set it at 65\% the then-existing average level of stable funding. Subsequently the requirement increased in two steps from $65 \%$ to $70 \%$ in July 2011, and then adjusted upward to $75 \%$ in January 2013. How does raising the required SFR level alter optimal monetary policy rules? Our benchmark is the estimated model, for which the steady-state model SFR is set at the sample mean. In this experiment, we 
proceed in three steps: (i) we remove the mild historical procyclicality of the requirement, setting $v_{\tau}=0$, (ii) we turn off SFR shocks, and then (iii) we raise the steady-state SFR.

The changes in losses under these alternative specifications are reported in the Panel (a) of Table 5 for the four loss functions described in the previous section. Historically, the stable funding ratio has tended to be weakly pro-cyclical. The posterior mode of $\nu_{\tau}$, the SFR response to the spread in Equation (33), is 0.41. In other words, the SFR has tended to rise a little when funding spreads have been high, and to ease when they have been low. Reflecting both the change in policy, and the statistical insignificance of the estimated value, we first set $\nu_{\tau}$ to zero. As shown in the second row of Panel (a) in Table 5, eliminating that mild pro-cyclical application of the SFR hardly affects monetary policy trade-offs, for all the loss functions we consider. The next row shows the effect of abstracting from the cyclical variation in the SFR, setting $\nu_{t}^{s f r}$ to zero. Removing the variation in the cyclical component reduces the monetary policy losses further, but the reduction is again small, reflecting the modest role of SFR shocks for loss function variables.

We then raise the steady-state $\mathrm{SFR}\left(\bar{\nu}^{s f r}\right)$ from 0.54 to 0.63 , then to 0.73 , and finally to 0.83, which are the adjusted model equivalents of the changes made to the requirement since its introduction. Observe that raising the steady-state level of the model SFR worsens monetary policy trade-offs materially, as compared to the experiments presented in the second and third rows.

We demonstrate that the worsening trade-offs at higher levels of the steady-state SFR are mainly associated with funding spread shocks. This can be seen from the bottom half of Panel (a) in Table 5, where we present results for the same set of experiments, but for the counter-factual scenario when spread shocks are deactivated. In that case, monetary policy trade-offs are largely invariant to the steady-state SFR level. The worsening trade-offs caused by spread shocks at higher steady-state SFR levels is better understood by examining the related features of the model environment and the impulse response functions generated by the spread shock.

The funding spread shock directly affects the demand function for one source of stable funding, namely long-term bonds, in Equation (23). On the other hand, the proportion of long-term bonds in the bank's balance sheet affects the bank's average cost of funds 
through Equation (13). The analogues of these two optimality conditions in the first-order approximation of the model are given as:

$$
\begin{gathered}
\Delta \hat{b}_{t}^{m}=\mathbb{E}_{t} \frac{1}{1+\bar{r}^{d}} \Delta \hat{b}_{t+1}^{m}-\frac{1}{\kappa^{m}(\bar{Q}+\bar{r})}\left(\bar{Q} \hat{\Psi}_{t}+\bar{r} \hat{\Phi}_{t}+\tilde{\tau}_{t}^{m}\right), \\
\text { and } \tilde{r}_{t}^{\ell}=\bar{\nu}^{s f r} \tilde{r}_{t}^{s f}+\left(1-\bar{\nu}^{s f r}\right) \tilde{r}_{t}+\bar{\tau}^{m} \bar{\nu}^{s f r}\left(\hat{b}_{t}^{s f}-\hat{\ell}_{t}\right) .
\end{gathered}
$$

When the steady-state $\operatorname{SFR}\left(\bar{\nu}^{s f r}\right)$ is high, the proportion of long-term bonds $\left(b^{m}\right)$ in the bank's balance sheet is raised. In this setting, an increase in the funding spread $\left(\tau^{m}\right)$ on the bonds pushes up the cost of stable funding $\left(r^{s f}\right)$ and in turn the internal loan rate $\left(r^{\ell}\right)$. The increase in the internal cost of funds increases the price of retail loans and depresses economic activity. This mechanism is key in generating the dynamics presented in Figure 2 which demonstrates how the economy responds to an exogenous widening of the funding spread for the different levels of the steady-state SFR.

The baseline estimated impulse responses with the steady-state SFR set at the sample mean of 0.54 are presented in solid black lines. As the steady-state share of stable funding rises, the economy's long-term bond holdings rise and it becomes increasingly sensitive to the rise in the bond spread. Accordingly, demand falls by more, leading to a larger monetary policy loosening, and through interest arbitrage, a larger exchange rate depreciation. Intuitively, a higher SFR amplifies the effect of spread shocks because the requirement is expensive to maintain in bad times when funding spreads rise. ${ }^{22}$ The additional volatility emanating from a higher steady-state SFR contributes to higher monetary policy losses. If spread shocks were the main source of business cycle fluctuations, monetary policy losses would be minimised if the long-run SFR is easened.

In stark contrast, the changes in the real-economy dynamics generated by varying the steady-state SFR are almost imperceptible, when we consider other shocks. For example, in Figure 3, in response to an exogenous rise in the policy interest rate, households withdraw deposits to smooth consumption, and banks replace that source of stable funding from a very liquid bond market. Recall that the posterior estimate of the bond adjustment cost parameter $\kappa_{m}$ is statistically not different from zero and hence banks can

\footnotetext{
${ }^{22}$ The role of the SFR as an amplifier of spread shocks is reminiscent of the role of bank capital requirements as an amplifier of business cycles (see e.g. Blum and Hellwig, 1995). Capital requirements are pro-cyclical since they raise the cost of issuing equity during downturns.
} 
increase bond-issuance almost costlessly. The real economy is hardly affected by changes in the steady-state SFR since it only alters the composition of bank funding; only the financial variables are affected.

We have seen that monetary policy trade-offs worsen as the steady-state level of the SFR is raised. What does this imply for the implementation of monetary policy? We examine the results for the model-specific loss function in Equation (39) that allows us to examine changes in the neighborhood of the estimated rule. As the steady-state level of the SFR is increased, we can see from Panel (b) of Table 5 that there is very little change in the parameterisation of the monetary policy rule $\left\{r_{r}^{o p t}, r_{\pi}^{o p t}, r_{y}^{o p t}\right\}$. Although the sensitivity of the economy to the cost of stable funding increases with the tightening steady-state SFR, and monetary policy trade-offs worsen, the implementation of monetary policy is hardly affected. The optimal coefficients remain in the vicinity of the estimated values. An important factor that explains this finding is that the spread shock, whose transmission is strongly influenced by the presence of the steady-state SFR, is not a dominant driver of the variables in the monetary policy loss function. For example, in the baseline estimation, the spread shock only contributes $0.74 \%$ of inflation volatility, $3.20 \%$ of output volatility and $11.74 \%$ of interest rate volatility (see Table 7 ) .

\subsection{Extending the monetary policy rule with financial variables}

In this section, we ask whether augmenting the monetary policy rule with financial variables can improve trade-offs while keeping the prudential instrument unchanged. In the next set of experiments, we include an additional term, $r_{x} x_{t}$, in the monetary policy reaction function:

$$
\tilde{r}_{t}=r_{R} \tilde{r}_{t-1}+\left(1-r_{R}\right)\left(r_{\pi} \mathbb{E}_{t} \tilde{\pi}_{c, t+1}+r_{y} \hat{y}_{t}+r_{x} x_{t}\right)
$$

where $x$ is an additional financial variable. We start with the funding spread and sequentially also consider measures of credit and asset prices. Given the model-specific loss function in Equation (39), we optimise over all monetary policy rule parameters, in the case of each financial variable. The baseline for all these experiments is the estimated 
model, but with $\nu_{\tau}$ set to zero, to eliminate the mild pro-cyclicality of the SFR estimated in the data. The results are summarised in Panel (a) of Table 6.

Losses decline relative to the baseline case, when monetary policy responds systematically to two variables related to credit growth; loan growth and the current account. Macroeconomic volatility is reduced (relative to baseline) when monetary policy is tightened in response to a rise in loan growth or to a larger current account deficit. In our model, the excess of loans disbursed by the bank over the deposits it receives is financed by borrowing from international financial markets. The current account is defined as the change in net foreign assets, i.e. the negative of the change in net foreign debt, and is effectively the excess of deposit growth over gross loan growth. The improvement in monetary policy trade-offs by responding to credit growth is in the spirit of the results of Quint and Rabanal (2014) and Lambertini, Mendicino, and Punzi (2013), who find support for a monetary response of 'leaning against the wind' to credit growth, in the context of a closed-economy. The similarity in results is particularly striking since these papers examine welfare-optimal policy in models of housing, and hence the objectives they pursue are considerably different from ours.

The optimal coefficients on loan growth (0.38) and the current account $(-0.06)$ are substantially larger than those for other variables. For example, the optimal monetary policy response to the spread is negative but very small at -0.0003 , despite the fact that the presence of the SFR amplifies the economy's response to disturbances to the funding spread. The other conventional monetary policy reaction function parameters do not materially change when alternative variables are used. In the next section, we abstract from financial variables in the monetary policy rule, and instead introduce additional variables in the macroprudential policy rule, to evaluate monetary policy trade-offs. We continue to focus on the model-specific loss function.

\subsection{Can a time-varying SFR policy improve monetary policy tradeoffs?}

In May 2013, a memorandum of understanding between the Reserve Bank and the Minister of Finance introduced the idea that the core funding requirement, the policy analogue 
of our model SFR, can be varied over time in response to the build-up of systemic risk. ${ }^{23}$ That is, banks may be required to increase the share of stable funding when systemic risk rises. To understand the impact of a time-varying SFR on the economy, we first demonstrate the dynamics triggered by the exogenous component of the SFR rule in Equation (33) in the estimated model. Figure 4 presents the response to an exogenous increase of 5 percentage points in the SFR from its steady-state value. The transitory rise in the SFR can be met by substituting from 1-period external funding to deposit or long-term bond funding, or by reducing both 1-period funding and loans. In the model, long-term bond markets are estimated to be very liquid $\left(\kappa_{m} \approx 0\right)$ and hence the cost of increasing bond funding is effectively the cost of shifting $5 \%$ of 1 -period funding to bond funding. Given the model calibration, the shift from short-term wholesale funding to long-term wholesale funding, translates to an additional cost of about 120 basis points per annum. The higher cost, applied to $5 \%$ of funding, increases the loan spread to about 6 basis points at the 1-year horizon. Higher debt service costs put pressure on the household budget, and consequently, the household reduces demand for loans and reduces expenditures on consumption and investment. The fall in demand puts downward pressure on inflation leading to a monetary policy easing of about the same magnitude as the initial spread shock.

Can time-variation in the SFR improve trade-offs from the monetary policy perspective? We now assess the monetary policy implications of a variety of SFR rules, abstracting from the exogenous component studied above. We use the same set of financial variables considered in the previous section, namely, interest rate spreads and measures of credit and asset prices. To assess the effects of a direct SFR response to those variables, we include an additional term $\nu_{x} x_{t}$ in the SFR policy rule:

$$
\tilde{\nu}_{t}^{s f r}=\rho_{s f r} \tilde{\nu}_{t-1}^{s f r}+\left(1-\rho_{s f r}\right)\left(\nu_{\tau} \tilde{\tau}_{t}^{m}+\nu_{x} x_{t}\right)
$$

where $x$ is the additional financial variable. How would the monetary authority recommend that SFR policy be implemented, to support the monetary policy function? ${ }^{24}$

\footnotetext{
${ }^{23}$ For details on the macroprudential toolkit of the Reserve Bank of New Zealand, see http://www . rbnz.govt.nz/financial_stability/macro-prudential_policy/5266657.html.

${ }^{24}$ To inform on what is desirable from a financial stability perspective, we would need to define a financial stability loss function, which is beyond the scope of the current paper. Angelini, Neri, and Panetta (2014) and Gelain and Ilbas (2014) examine issues of strategic coordination between monetary
} 
We continue to set the SFR response to the bond spread $\nu_{\tau}$ to zero, in order to remove the mild procyclicality estimated in the historical data. We present the optimised coefficients and associated changes in monetary policy losses, in Panel (b) of Table 6. A striking similarity with the results for the optimised augmented monetary policy rules in Panel (a), is that systematic SFR responses to the current account (i.e., the negative of net loan growth), diminish monetary policy welfare losses. The optimal coefficient for this variable is negative, implying that a tightening of the SFR when the current account deficit worsens reduces macroeconomic volatility. We also observe that losses are reduced when the SFR reacts to other measures of credit such as loans and net foreign debt, or asset prices. However the signs of the optimal coefficients, for example a loosening of the SFR for a rise in loans, are counter-intuitive. ${ }^{25}$

Overall, our results indicate that the presence of the time-varying SFR leaves lossmiminising monetary policy rule coefficients relatively unchanged. These results can again be explained by the weight on the time-varying ratio of long-term bonds to loans, in the internal cost of loans in Equation (41). Observe that the steady-state funding spread $\bar{\tau}^{m}$ determines the influence of the share of long-term liabilities which is in turn regulated by the SFR. This key parameter is given a very small value in the calibration - at the sample mean of $0.38 \%$. Hence it is not surprising that the time-varying share of long-term bonds, which the cyclical component of the SFR directly influences, plays little role in influencing the bank's cost of funds and is consequently hardly influential in determining the dynamics of the economy. The result that optimised monetary policy rules remain very similar to the baseline case, suggests that monetary and macroprudential policy can be operated independently.

\section{Conclusion}

This paper contributes to our understanding of the macroeconomic consequences of the Basel III net stable funding ratio scheduled to come into force in 2018 . We develop and

policy and capital requirements, using separate loss functions for the monetary and macroprudential authorities.

${ }^{25}$ Optimal SFR and monetary policy responses to movements in the current account, reduce macroeconomic volality even when we use loss functions from the literature presented in Equations (34), (35), and (36). However, the optimal coefficients underpinning the result in these experiments, are at times empirically unrealistic. These additional results are available on request. 
estimate a DSGE model featuring a stable funding requirement, for New Zealand where a similar regulation has been operational since 2010. The stable funding requirement regulates the proportion of the bank's liabilities held in long-term bonds and deposits, as opposed to short-term wholesale funding. The model was estimated for New Zealand where a similar policy instrument has been operational since 2010. Finally, we evaluated the implications of the macroprudential instrument for monetary policy trade-offs and assessed the effects on optimal policy rules derived from the central bank's loss function.

Taking into account the influence of all the estimated structural shocks, the presence of the stable funding requirement makes little difference to loss-minimising monetary policy rules, since it only alters the composition of bank funding. However, conditional on the bank funding spread shock which makes long-term financing expensive, the stable funding requirement worsens volatility-based losses. This finding is explained by the role of the stable funding requirement as an amplifier of the transmission of spread shocks; if a higher proportion of the bank's liabilities are held in long-term bonds when the spreads on these bonds rise, the effect on domestic lending rates is stronger and hence economic activity contracts further. We find that this additional volatility can be reduced if monetary policy 'leans against the wind' by responding directly to measures of credit - loan growth and the current account - so that the economy's exposure to the funding spread shock is limited. In a similar vein, monetary policy losses can also be reduced, if the prudential tool reacts to the current account. Even so, the optimal monetary policy responses to inflation and the output-gap do not change substantially. From the perspective of the monetary policy loss function, monetary and prudential policies can be operated independently.

Our results are conditional on several constraints imposed by our modelling choices. The economic environment featuring a small open economy that is exposed to bank funding spread shocks in international financial markets, has been designed to suit specific aspects of the New Zealand economy. While this approach provides a flavour of the implications of the stable funding requirement once it is enforced in similar economies, it may be less suitable to apply to larger economies where domestic developments may exert greater influence over their cost of borrowing. On the technical dimension, we have allowed for longer maturities on the liability side of the bank's balance sheet, and that cost-structure is passed through to loans. In terms of cost-structure, the bank does 
not engage in maturity transformation. Hence, the prudential policy may have different effects when the bank engages in maturity transformation, e.g. as in Andreasen, Ferman, and Zabczyk (2013). As far as modelling the prudential instrument is concerned, we have used a conventional symmetric function to penalise deviations from the stable funding requirement. A more realistic approach would be to impose a floor on the share of stable funding and penalise any deviation that falls below the target floor. Incorporating that non-linearity would entail the use of more complex solution strategies, moving beyond the class of the linearised general equilibrium models used in this paper. We leave these extensions for future research.

\section{References}

Acharya, V. and D. Skeie (2011), A Model of Liquidity Hoarding and Term Premia in Inter-Bank Markets, Journal of Monetary Economics, 58(5), 436-447.

Adjemian, S., H. Bastani, F. Karamé, M. Juillard, J. Maih, F. Mihoubi, G. Perendia, J. Pfeifer, M. Ratto, and S. Villemot (2011), Dynare: Reference Manual Version 4, Dynare working papers, CEPREMAP.

Adolfson, M., S. Laséen, J. Lindé, and M. Villani (2007), Bayesian Estimation of an Open-Economy DSGE Model with Incomplete Pass-through, Journal of International Economics, 72(2), 481-511.

Alpanda, S., G. Cateau, and C. Meh (2014), A Policy Model to Analyze Macroprudential Regulations and Monetary Policy, Working Papers 14-6, Bank of Canada.

An, S. and F. Schorfheide (2007), Bayesian Analysis of DSGE Models, Econometric Reviews, 26(2-4), 113-172.

Andreasen, M., M. Ferman, and P. Zabczyk (2013), The Business Cycle Implications of Banks' Maturity Transformation, Review of Economic Dynamics, 16(4), $581-600$.

Angelini, P., S. Neri, and F. Panetta (2014), The Interaction between Capital Requirements and Monetary Policy, Journal of Money, Credit and Banking, 46(6), $1073-1112$.

Angeloni, I. and E. Faia (2013), Capital Regulation and Monetary Policy with Fragile Banks, Journal of Monetary Economics, 60(3), 311-324.

Benes, J. and K. Lees (2010), Multi-Period Fixed-Rate Loans, Housing and Monetary Policy in Small Open Economies, Reserve Bank of New Zealand Discussion Paper Series DP2010/03, Reserve Bank of New Zealand.

Bergin, P. (2003), Putting the 'New Open Economy Macroeconomics' to a Test, Journal of International Economics, 60(1), 3-34. 
Blum, J. and M. Hellwig (1995), The macroeconomic implications of capital adequacy requirements for banks, European Economic Review, 39(3-4), 739-749.

Bollard, A. (2004), Supervising Overseas-owned Banks: New Zealand's Experience: A Speech to the Trans-Tasman Business Circle in Sydney, 11 August 2004, Speech, Reserve Bank of New Zealand.

Brzoza-Brzezina, M., P. Gelain, and M. Kolasa (2014), Monetary and Macroprudential Policy with Multi-period Loans, Working Paper 2014/16, Norges Bank.

Christiano, L., R. Motto, and M. Rostagno (2014), Risk Shocks, American Economic Review, 104(1), 27-65.

Covas, F. and S. Fujita (2010), Procyclicality of Capital Requirements in a General Equilibrium Model of Liquidity Dependence, International Journal of Central Banking, 6(34), 137-173.

de Walque, G., O. Pierrard, and A. Rouabah (2010), Financial (In)Stability, Supervision and Liquidity Injections: A Dynamic General Equilibrium Approach, Economic Journal, 120(549), 1234-1261.

Dennis, R. (2006), The Policy Preferences of the US Federal Reserve, Journal of Applied Econometrics, 21(1), 55-77.

Gali, J. and T. Monacelli (2005), Monetary Policy and Exchange Rate Volatility in a Small Open Economy, Review of Economic Studies, 72(3), 707-734.

Gelain, P. and P. Ilbas (2014), Monetary and Macroprudential Policies in an Estimated Model with Financial Intermediation, Working Paper Research 258, National Bank of Belgium.

Gerali, A., S. Neri, L. Sessa, and F. Signoretti (2010), Credit and Banking in a DSGE Model of the Euro Area, Journal of Money, Credit and Banking, 42(s1), $107-141$.

Gertler, M. and P. Karadi (2011), A Model of Unconventional Monetary Policy, Journal of Monetary Economics, 58(1), 17-34.

Gertler, M., N. Kiyotaki, and A. Queralto (2012), Financial Crises, Bank Risk Exposure and Government Financial Policy, Journal of Monetary Economics, 59(S), S17-S34.

Geweke, J. (1999), Using Simulation Methods for Bayesian Econometric Models: Inference, Development, and Communication, Econometric Reviews, 18(1), 1-73.

Goodfriend, M. and B. McCallum (2007), Banking and Interest Rates in Monetary Policy Analysis: A Quantitative Exploration, Journal of Monetary Economics, 54(5), 1480-1507.

Ilbas, P. (2012), Revealing the Preferences of the US Federal Reserve, Journal of Applied Econometrics, 27(3), 440-473. 
Jermann, U. and V. Quadrini (2012), Macroeconomic Effects of Financial Shocks, American Economic Review, 102(1), 238-71.

Justiniano, A. and B. Preston (2010), Monetary Policy and Uncertainty in an Empirical Small Open-Economy Model, Journal of Applied Econometrics, 25(1), 93-128.

Kam, T., K. Lees, and P. Liu (2009), Uncovering the Hit List for Small Inflation Targeters: A Bayesian Structural Analysis, Journal of Money, Credit and Banking, 41(4), 583-618.

Kamber, G., C. McDonald, N. Sander, and K. Theodoridis (2015), A Structural Model for Policy Analysis and Forecasting: NZSIM, Reserve Bank of New Zealand Discussion Paper Series DP2015/05, Reserve Bank of New Zealand.

Lambertini, L., C. Mendicino, and M. T. Punzi (2013), Leaning against BoomBust Cycles in Credit and Housing Prices, Journal of Economic Dynamics and Control, 37(8), 1500-1522.

Lubik, T. A. and F. Schorfheide (2007), Do Central Banks respond to Exchange Rate Movements? A Structural Investigation, Journal of Monetary Economics, 54(4), 1069-1087.

Quint, D. and P. Rabanal (2014), Monetary and Macroprudential Policy in an Estimated DSGE Model of the Euro Area, International Journal of Central Banking, 10(2), 169-236.

Roger, S. and J. Vlcek (2011), Macroeconomic Costs of Higher Bank Capital and Liquidity Requirements, IMF Working Papers 11/103, International Monetary Fund.

Rotemberg, J. (1982), Monopolistic Price Adjustment and Aggregate Output, Review of Economic Studies, 49(4), 517-31.

Shin, H. S. and K. Shin (2011), Procyclicality and Monetary Aggregates, NBER Working Papers 16836, National Bureau of Economic Research, Inc.

Smets, F. and R. Wouters (2007), Shocks and Frictions in US Business Cycles: A Bayesian DSGE Approach, American Economic Review, 97(3), 586-606.

Van den Heuvel, S. (2008), The Welfare Cost of Bank Capital Requirements, Journal of Monetary Economics, 55(2), 298-320.

Woodford, M. (2001), Fiscal Requirements for Price Stability, Journal of Money, Credit and Banking, 33(3), 669-728. 
Figure 1: The Stable Funding Requirement and the Funding Spread in New Zealand

(a) The Stable Funding Ratio: Timeline

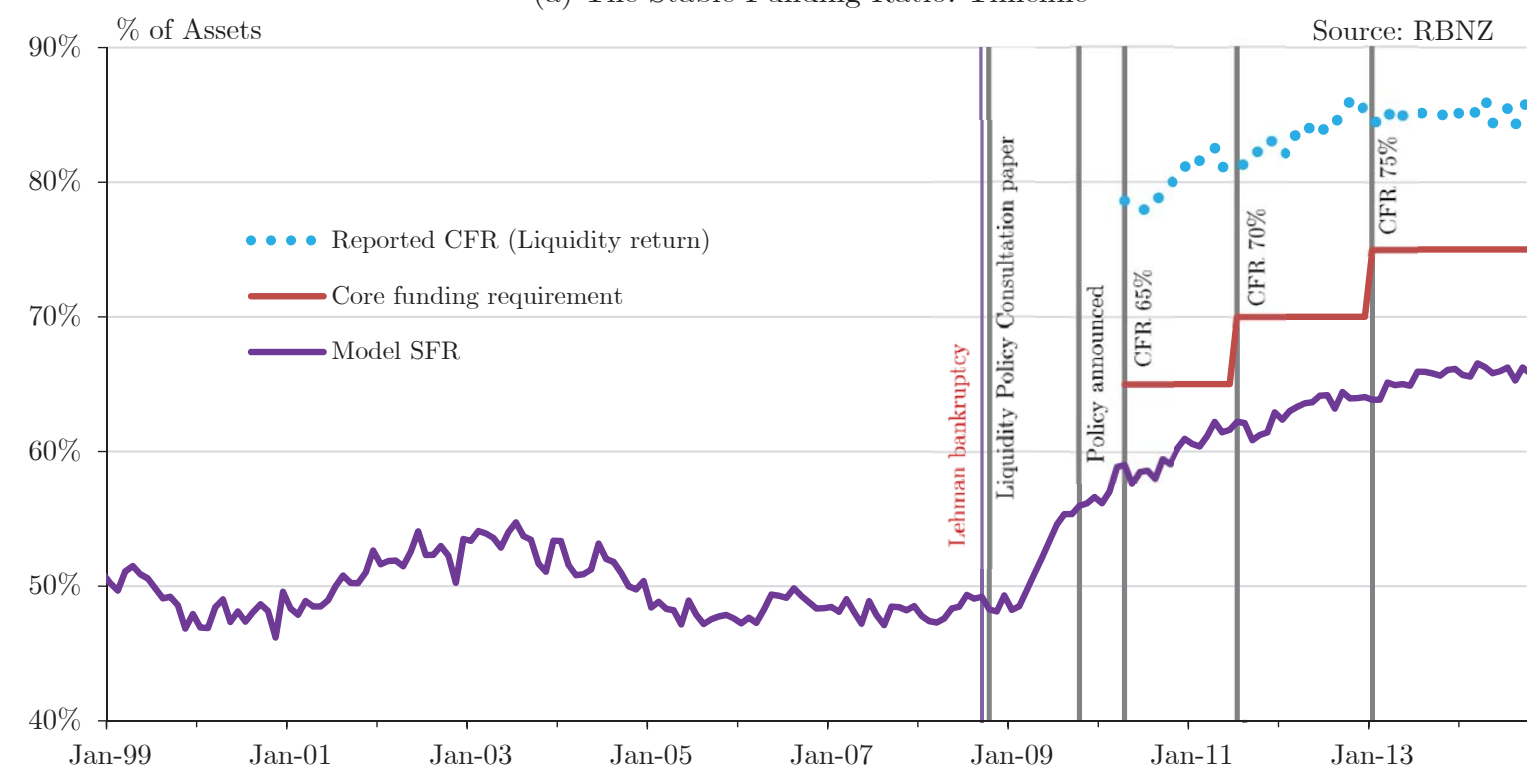

Note: The definitions of the model SFR and the New Zealand Core Funding Requirement (CFR) are slightly different. The CFR includes equity capital which is not in our model, and its denominator is less liquid assets. The model SFR is defined as deposits plus long-term wholesale funding divided by total funding ex-capital.

(b) Benchmark Interest Rates and Bond Spreads

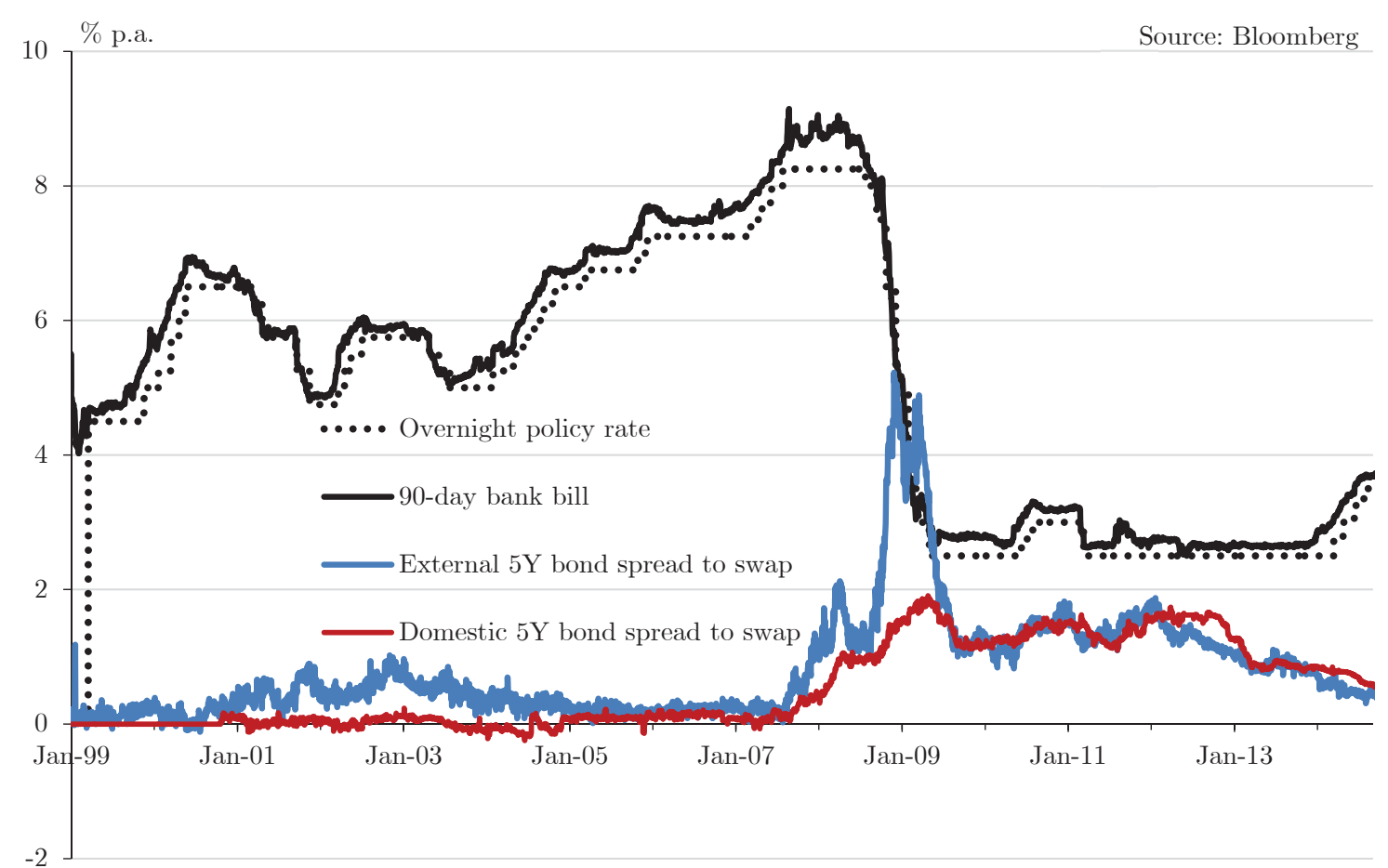

Note: External bond spread is USD AA 5Y finance bond yield less USD 5Y interest rate swap plus NZD cross currency basis swap. The interest rate swap is the expected cost of short-term funding over a longer horizon and includes a term premium. The basis swap is the cost of swapping USD funding to NZD. 

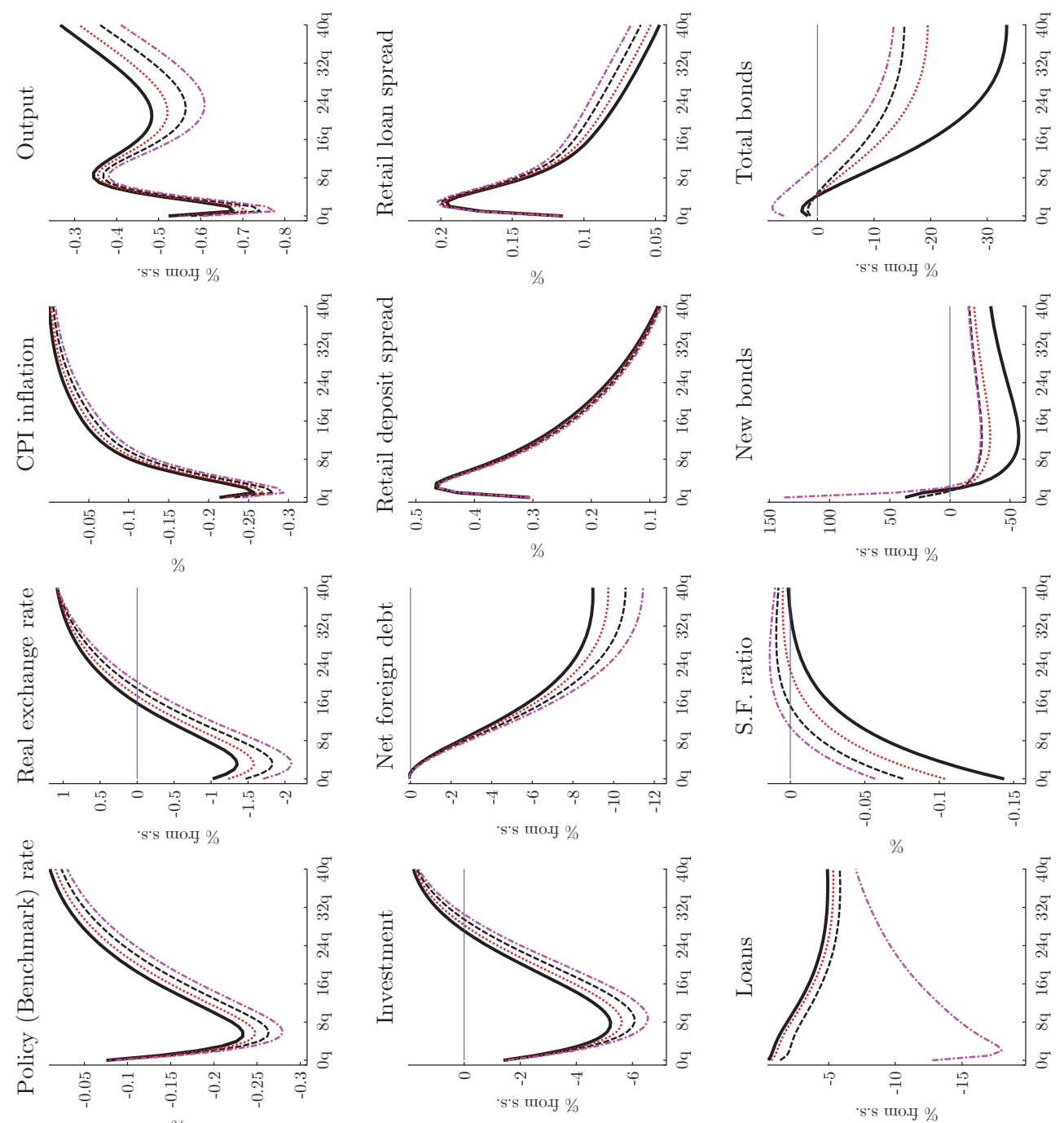

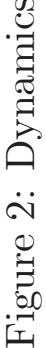
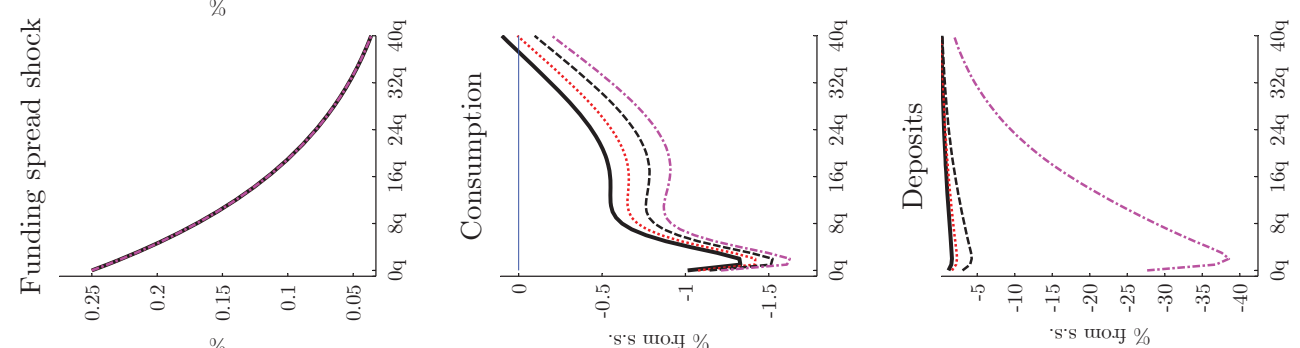

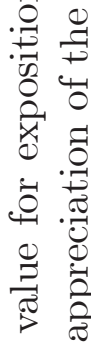

궁

范

氙

8.

+

$+8$

웡

. .

궁

क .

g.

प्山 4

.

의

훙

苍焉 







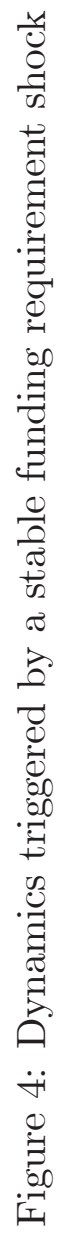
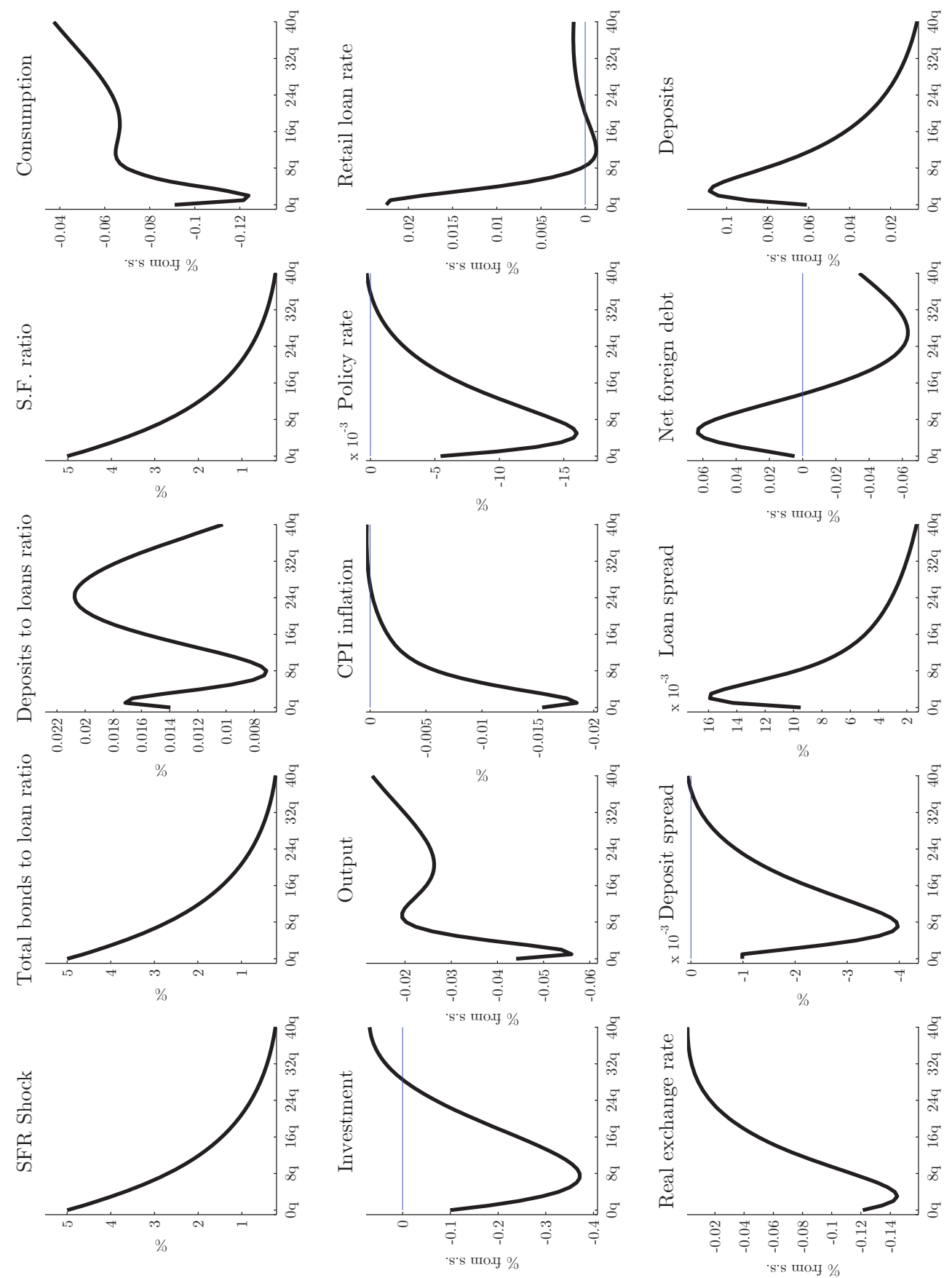

$\Xi$

.용 


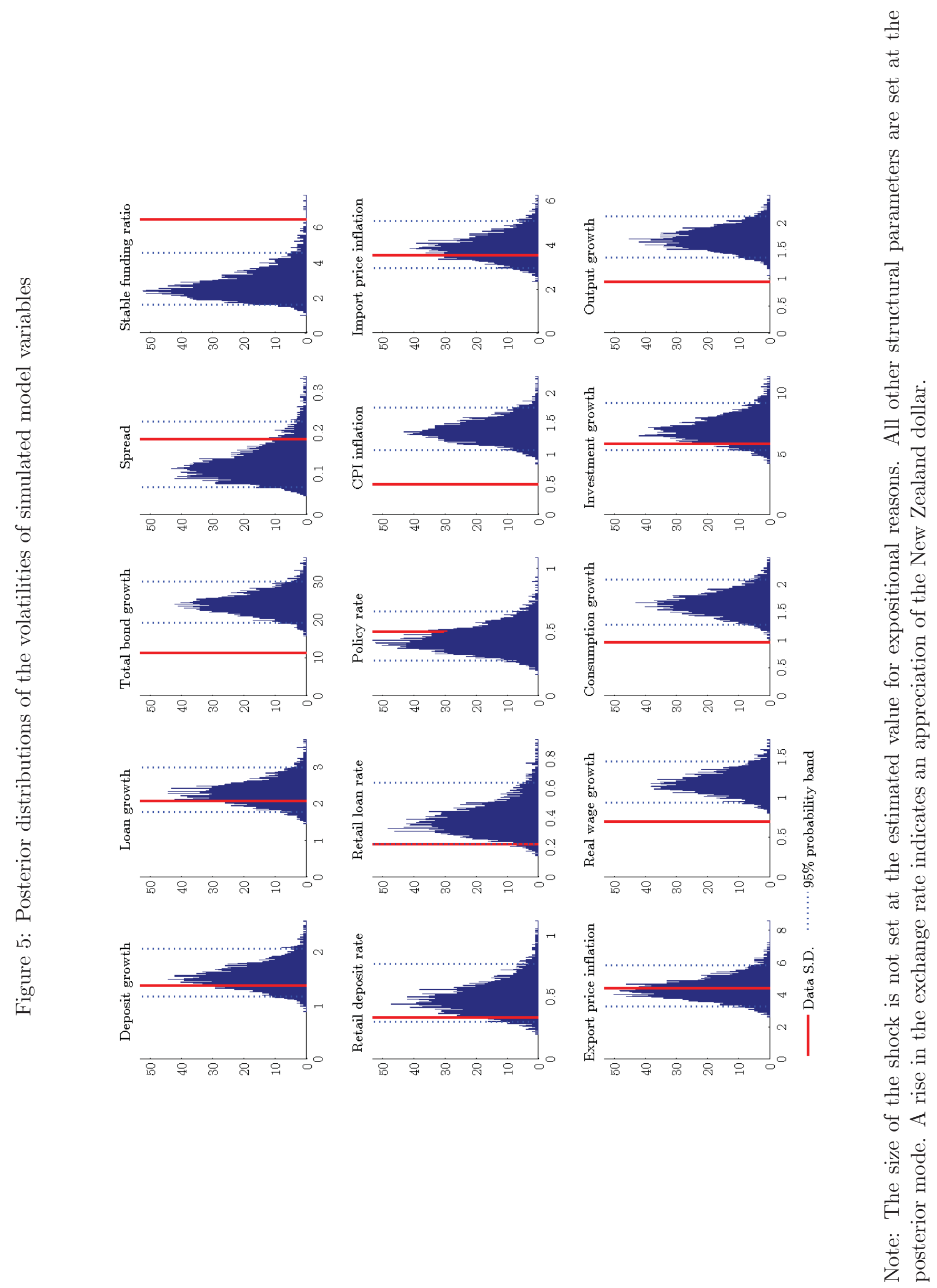




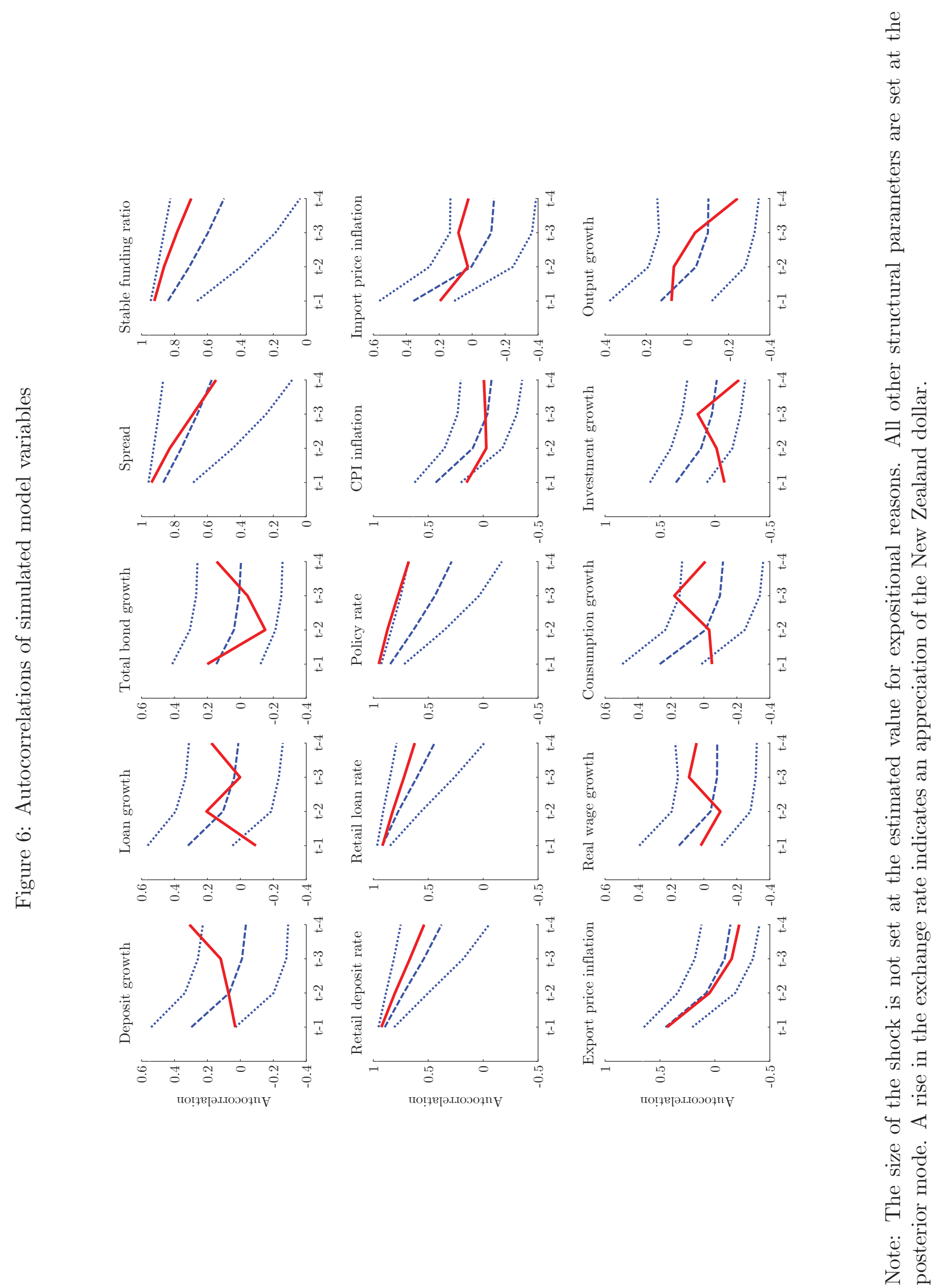




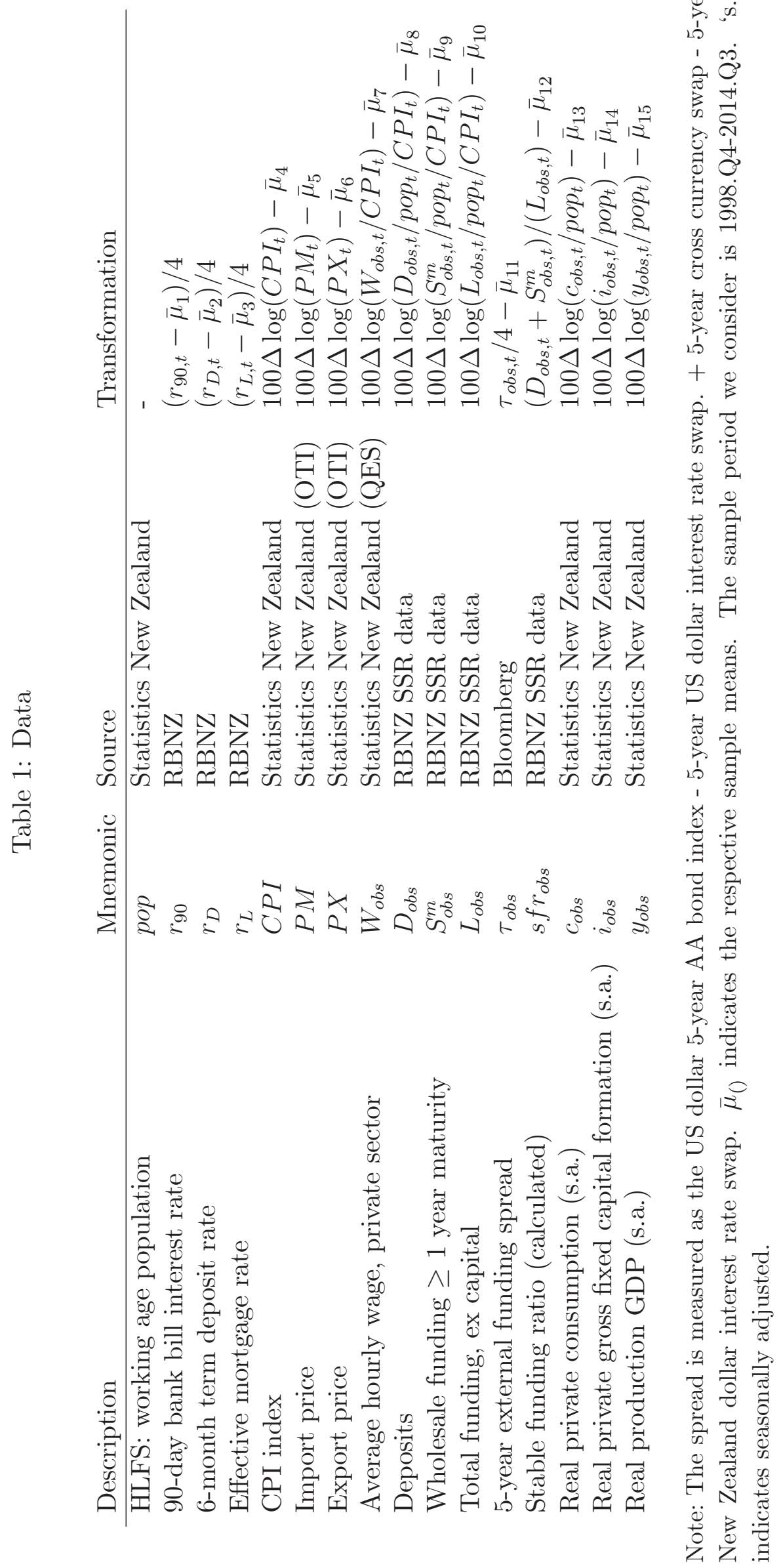


Table 2: Prior and posterior distributions of structural parameters

\begin{tabular}{|c|c|c|c|c|c|}
\hline \multirow{2}{*}{$\begin{array}{l}\text { Parameter } \\
\text { Symbol }\end{array}$} & \multirow[b]{2}{*}{ Description } & \multirow[b]{2}{*}{ Prior $\left(\mathrm{p}_{1}, \mathrm{p}_{2}\right)$} & \multicolumn{3}{|c|}{ Posterior statistics } \\
\hline & & & Mode & $2.5 \%$ ile & $97.5 \%$ ile \\
\hline$\gamma_{2}$ & Curvature of SFR cost function & $\mathbb{N}(5,1.5)$ & 5.02 & 2.23 & 7.89 \\
\hline$\omega_{d}$ & Elasticity of deposit demand & $\mathbb{N}(50,200)$ & 111.92 & 77.93 & 354.44 \\
\hline$\kappa^{L}$ & Retail loan rate adjustment cost & $\mathbb{N}(5,1.5)$ & 9.49 & 7.47 & 11.79 \\
\hline$\kappa^{D}$ & Retail deposit rate adjustment cost & $\mathbb{N}(5,1.5)$ & 7.27 & 5.04 & 9.67 \\
\hline$\kappa^{m}$ & Bond adjustment cost & $\mathbb{N}(0.1,1)$ & 0 & 0 & 0 \\
\hline$\nu_{\tau}$ & SFR reaction to spread & $\mathbb{N}(0,1)$ & 0.41 & -1.51 & 2.38 \\
\hline$\gamma_{c}$ & External habit & $\mathbb{B}(0.40,0.05)$ & 0.47 & 0.38 & 0.57 \\
\hline$\phi_{i}$ & Investment adjustment cost & $\mathbb{N}(5,1)$ & 4.81 & 3.52 & 6.55 \\
\hline$\chi_{p d}$ & Domestic sales price adjustment cost & $\mathbb{N}(205,25)$ & 131.82 & 92.35 & 174.34 \\
\hline$\iota_{p d}$ & Domestic sales price indexation & $\mathbb{B}(0.50,0.10)$ & 0.26 & 0.16 & 0.41 \\
\hline$\chi_{p m}$ & Import sales price adjustment cost & $\mathbb{N}(229,25)$ & 222.87 & 172.87 & 270.09 \\
\hline$\iota_{p m}$ & Import sales price indexation & $\mathbb{B}(0.50,0.10)$ & 0.29 & 0.17 & 0.44 \\
\hline$\chi_{p x}$ & Export sales price adjustment cost & $\mathbb{N}(769,25)$ & 765.21 & 715.18 & 815.82 \\
\hline$\iota_{p x}$ & Export sales price indexation & $\mathbb{B}(0.50,0.10)$ & 0.36 & 0.22 & 0.51 \\
\hline$\chi_{w}$ & Nominal wage adjustment cost & $\mathbb{N}(249,25)$ & 303.22 & 259.77 & 349.01 \\
\hline$\iota_{w}$ & Nominal wage indexation & $\mathbb{B}(0.50,0.10)$ & 0.40 & 0.25 & 0.59 \\
\hline$r_{R}$ & Policy rate smoothing & $\mathbb{B}(0.75,0.05)$ & 0.85 & 0.81 & 0.88 \\
\hline$r_{\pi}$ & Policy rate reaction to inflation & $\mathbb{G}(2,0.10)$ & 1.96 & 1.78 & 2.16 \\
\hline$r_{y}$ & Policy rate reaction to output & $\mathbb{N}(0.15,0.10)$ & 0.04 & -0.04 & 0.15 \\
\hline $\bar{\beta}$ & S.S. discount factor & 0.9879 & & - & \\
\hline $\bar{\beta} \beta_{c}$ & Elasticity of discount factor (rescaled) & 0.01 & & - & \\
\hline$\delta_{k}$ & Capital depreciation & 0.025 & & - & \\
\hline$\alpha$ & Capital share of production & 0.30 & & - & \\
\hline$m_{c}$ & Import-share of consumption & 0.20 & & - & \\
\hline$m_{i}$ & Import-share of investment & 0.68 & & - & \\
\hline$\eta_{c}, \eta_{i}$ & Price elasticities of import demand & 0.52 & & - & \\
\hline$\eta_{x}$ & Price elasticity of export demand & 0.81 & & - & \\
\hline $\bar{\mu}_{()}$ & S.S. price and wage markups & 1.1 & & - & \\
\hline$\omega_{n}$ & Inverse of Frisch elasticity of labour & 1.34 & & - & \\
\hline $\bar{y}_{x} / \bar{y}$ & S.S.exports to output ratio & 0.31 & & - & \\
\hline$\overline{e s} / \bar{y}$ & S.S.exogenous spending to output ratio & 0.18 & & - & \\
\hline $\bar{\mu}^{L}$ & S.S. loan markup & 1.4 & & - & \\
\hline $\bar{\mu}^{D}$ & S.S.deposit markdown & 0.76 & & - & \\
\hline $\bar{d} / \bar{y}$ & S.S. deposits to output ratio & 3.2 & & - & \\
\hline $\bar{\tau}^{m}$ & S.S. spread & 0.0038 & & - & \\
\hline $\bar{d}^{m}$ & Average duration of bonds & 20 & & - & \\
\hline $\bar{\nu}^{s f r}$ & S.S. SFR & 0.54 & & - & \\
\hline$\overline{n f d} / \bar{y}$ & S.S. net foreign debt to output ratio & 2.8 & & - & \\
\hline
\end{tabular}

Note: $\mathbb{G} \equiv$ Gamma distribution, $\mathbb{B} \equiv$ Beta distribution, $\mathbb{I} \mathbb{G} \equiv$ Inverse gamma distribution and $\mathbb{N} \equiv$ Normal distribution. $\mathrm{p}_{1} \equiv$ mean and $\mathrm{p}_{2} \equiv$ standard deviation for all distributions. S.S. represents steady-state. Other steady-state parameters are derived from the restrictions of the model. Posterior moments are computed from 5000 random draws from the simulated posterior distribution. 
Table 3: Prior and posterior distributions of shock parameters

\begin{tabular}{|c|c|c|c|c|c|}
\hline \multirow{2}{*}{$\begin{array}{l}\text { Parameter } \\
\text { Symbol }\end{array}$} & \multirow[b]{2}{*}{ Description } & \multirow[b]{2}{*}{ Prior $\left(\mathrm{p}_{1}, \mathrm{p}_{2}\right)$} & \multicolumn{3}{|c|}{ Posterior statistics } \\
\hline & & & Mode & $2.5 \%$ ile & $97.5 \%$ ile \\
\hline$\rho_{L}$ & AR(1) Loan markup shock & $\mathbb{B}(0.50,0.10)$ & 0.83 & 0.70 & 0.91 \\
\hline$\rho_{D}$ & AR(1) Deposit markdown shock & $\mathbb{B}(0.50,0.10)$ & 0.76 & 0.65 & 0.84 \\
\hline$\rho_{\tau}$ & AR(1) Spread shock & $\mathbb{B}(0.50,0.10)$ & 0.95 & 0.95 & 0.95 \\
\hline$\rho_{s f r}$ & AR(1) SFR Shock & $\mathbb{B}(0.50,0.10)$ & 0.93 & 0.88 & 0.95 \\
\hline$\rho_{m p}$ & AR(1) Monetary policy shock & $\mathbb{B}(0.50,0.10)$ & 0.35 & 0.24 & 0.47 \\
\hline$\rho_{\beta}$ & AR(1) Consumption shock & $\mathbb{B}(0.50,0.10)$ & 0.59 & 0.39 & 0.71 \\
\hline$\rho_{i}$ & AR(1) Investment shock & $\mathbb{B}(0.50,0.10)$ & 0.33 & 0.20 & 0.48 \\
\hline$\rho_{e s}$ & AR(1) Exogenous spending shock & $\mathbb{B}(0.50,0.10)$ & 0.77 & 0.65 & 0.85 \\
\hline$\rho_{t f p}$ & AR(1) Technology shock & $\mathbb{B}(0.50,0.10)$ & 0.32 & 0.19 & 0.44 \\
\hline$\rho_{p m}$ & AR(1) Import price markup shock & $\mathbb{B}(0.50,0.10)$ & 0.26 & 0.15 & 0.38 \\
\hline$\rho_{p x}$ & AR(1) Export price markup shock & $\mathbb{B}(0.50,0.10)$ & 0.30 & 0.19 & 0.43 \\
\hline$\rho_{w}$ & AR(1) Wage markup shock & $\mathbb{B}(0.50,0.10)$ & 0.41 & 0.27 & 0.54 \\
\hline$\rho_{\Delta \ell}^{m e}$ & AR(1) Measurement error for loans & $\mathbb{B}(0.50,0.10)$ & 0.27 & 0.16 & 0.44 \\
\hline$\rho_{\Delta d}^{m e}$ & AR(1) Measurement error for deposits & $\mathbb{B}(0.50,0.10)$ & 0.31 & 0.19 & 0.48 \\
\hline$\rho_{\Delta b}^{m e}$ & AR(1) Measurement error for bonds & $\mathbb{B}(0.50,0.10)$ & 0.31 & 0.19 & 0.48 \\
\hline$\sigma_{L}$ & SD Loan markup shock & $\mathbb{I} \mathbb{G}(0.10,2)$ & 0.03 & 0.03 & 0.04 \\
\hline$\sigma_{D}$ & SD Deposit markup shock & $\mathbb{I} \mathbb{G}(0.10,2)$ & 0.11 & 0.09 & 0.16 \\
\hline$\sigma_{\tau}$ & SD Spread shock & $\mathbb{I} \mathbb{G}(0.10,2)$ & 0.05 & 0.05 & 0.06 \\
\hline$\sigma_{s f r}$ & SD SFR shock & $\mathbb{I} \mathbb{G}(0.10,2)$ & 1.26 & 1.09 & 1.59 \\
\hline$\sigma_{m p}$ & SD Monetary policy shock & $\mathbb{I} \mathbb{G}(0.10,2)$ & 0.12 & 0.10 & 0.15 \\
\hline$\sigma_{\beta}$ & SD Consumption shock & $\mathbb{I} \mathbb{G}(0.10,2)$ & 0.34 & 0.25 & 0.52 \\
\hline$\sigma_{i}$ & SD Investment shock & $\mathbb{I} \mathbb{G}(0.10,2)$ & 2.37 & 1.94 & 2.97 \\
\hline$\sigma_{e s}$ & SD Exogenous spending shock & $\mathbb{I} \mathbb{G}(0.10,2)$ & 1.08 & 0.94 & 1.33 \\
\hline$\sigma_{t f p}$ & SD Technology shock & $\mathbb{I} \mathbb{G}(0.10,2)$ & 0.49 & 0.41 & 0.61 \\
\hline$\sigma_{p m}$ & SD Import price markup shock & $\mathbb{I} \mathbb{G}(0.10,2)$ & 2.58 & 2.15 & 3.18 \\
\hline$\sigma_{p x}$ & SD Export price markup shock & $\mathbb{I} \mathbb{G}(0.10,2)$ & 2.47 & 2.03 & 3.08 \\
\hline$\sigma_{w}$ & SD Wage markup shock & $\mathbb{I} \mathbb{G}(0.10,2)$ & 0.72 & 0.58 & 0.94 \\
\hline$\sigma_{\Delta \ell}^{m e}$ & SD Measurement error for loans & $\mathbb{I} \mathbb{G}(0.10,2)$ & 1.93 & 1.66 & 2.40 \\
\hline$\sigma_{\Delta d}^{m e}$ & SD Measurement error for deposits & $\mathbb{I} \mathbb{G}(0.10,2)$ & 1.29 & 1.12 & 1.63 \\
\hline$\sigma_{\Delta b}^{m e}$ & SD Measurement error for bonds & $\mathbb{I} \mathbb{G}(0.10,2)$ & 14.47 & 12.46 & 17.70 \\
\hline
\end{tabular}

Note: $\mathbb{G} \equiv$ Gamma distribution, $\mathbb{B} \equiv$ Beta distribution, $\mathbb{I} \mathbb{G} \equiv$ Inverse gamma distribution and $\mathbb{N} \equiv$ Normal distribution. $\mathrm{p}_{1} \equiv$ mean and $\mathrm{p}_{2} \equiv$ standard deviation for all distributions. 
Table 4: Optimal monetary policy rules for various loss functions

\begin{tabular}{|c|c|c|c|c|}
\hline \multicolumn{3}{|c|}{ Optimal coefficients ${ }^{\mathrm{a}}$} & \multirow[t]{2}{*}{ Distance $^{\mathrm{b}}$} & Loss function weights ${ }^{c}$ \\
\hline$r_{R}^{o p t}$ & $r_{\pi}^{o p t}$ & $r_{y}^{\text {opt }}$ & & $\theta_{(\pi)} \theta_{\left(x_{1}\right)}$ \\
\hline
\end{tabular}

\begin{tabular}{l|ccccccc}
$\begin{array}{l}\text { 1-variable loss function } \\
\tilde{\pi}_{t}\end{array}$ & 0.488 & 88.24 & -2.56 & 87.44 & 1 & - & - \\
3-variable loss functions & & & & & & & \\
$\tilde{\pi}_{t}, \hat{y}_{t}, \tilde{r}_{t}$ & 0.935 & 1.977 & 0.388 & 0.36 & 1 & 0.36 & 3.48 \\
$\tilde{\pi}_{t}, \hat{y}_{t}, \Delta \tilde{r}_{t}$ & 0.913 & 1.985 & 0.401 & 0.37 & 1 & 0.24 & 4.34 \\
$\tilde{\pi}_{t}, \hat{y}_{t}, \widehat{r e r}_{t}$ & 0.799 & 1.969 & 0.242 & 0.21 & 1 & - & 0.14 \\
$\tilde{\pi}_{t}, \hat{y}_{t}, \Delta \widehat{r e r}_{t}$ & 0.803 & 1.964 & 0.022 & 0.05 & 1 & - & 0.33 \\
$\tilde{\pi}_{t}, \Delta \hat{y}_{t}, \tilde{r}_{t}$ & 0.398 & 11.030 & -0.570 & 9.10 & 1 & 0.36 & - \\
$\tilde{\pi}_{t}, \Delta \hat{y}_{t}, \Delta \tilde{r}_{t}$ & 0.400 & 12.538 & -0.654 & 10.61 & 1 & 1.35 & - \\
$\tilde{\pi}_{t}, \Delta \hat{y}_{t}, \widehat{r e r}_{t}$ & 0.799 & 1.969 & 0.242 & 0.21 & 1 & 0.18 & 0.14 \\
$\tilde{\pi}_{t}, \Delta \hat{y}_{t}, \Delta \widehat{r e r}_{t}$ & 0.803 & 1.964 & 0.022 & 0.05 & 1 & 0.09 & 0.33 \\
$\tilde{\pi}_{t}, \tilde{r}_{t}, \widehat{r e r}_{t}$ & 0.896 & 1.963 & 0.197 & 0.16 & 1 & 3.19 & 0.16 \\
$\tilde{\pi}_{t}, \tilde{r}_{t}, \Delta \widehat{r e r}_{t}$ & 0.857 & 1.959 & 0.035 & 0.009 & 1 & 1.74 & 0.55 \\
$\tilde{\pi}_{t}, \Delta \tilde{r}_{t}, \widehat{r e r}_{t}$ & 0.839 & 1.967 & 0.222 & 0.18 & 1 & 1.24 & 0.12 \\
$\tilde{\pi}_{t}, \Delta \tilde{r}_{t}, \Delta \widehat{r e r}_{t}$ & 0.866 & 1.958 & 0.041 & 0.015 & 1 & 6.82 & 0.44
\end{tabular}

a. The monetary policy reaction function shown for each class of loss function, is the closest to the estimated rule among all rules computed across the set of loss function weights.

b. Distance is defined as the square root of the sum of the squared differences between the estimated Taylor rule parameters $\left(r_{R}=0.851, r_{\pi}=1.960, r_{y}=0.042\right)$ and the coefficients from the optimal policy rule for that loss function specification.

c. The range of loss function weights that we use for the grid-search is: $\theta_{y} \in[0,0.8], \theta_{\Delta y} \in$ $[0,1.7], \theta_{r} \in[0,5.8], \theta_{\Delta r} \in[0,12.3], \theta_{r e r} \in[0,0.4]$ and $\theta_{\Delta r e r} \in[0,2.2]$. 


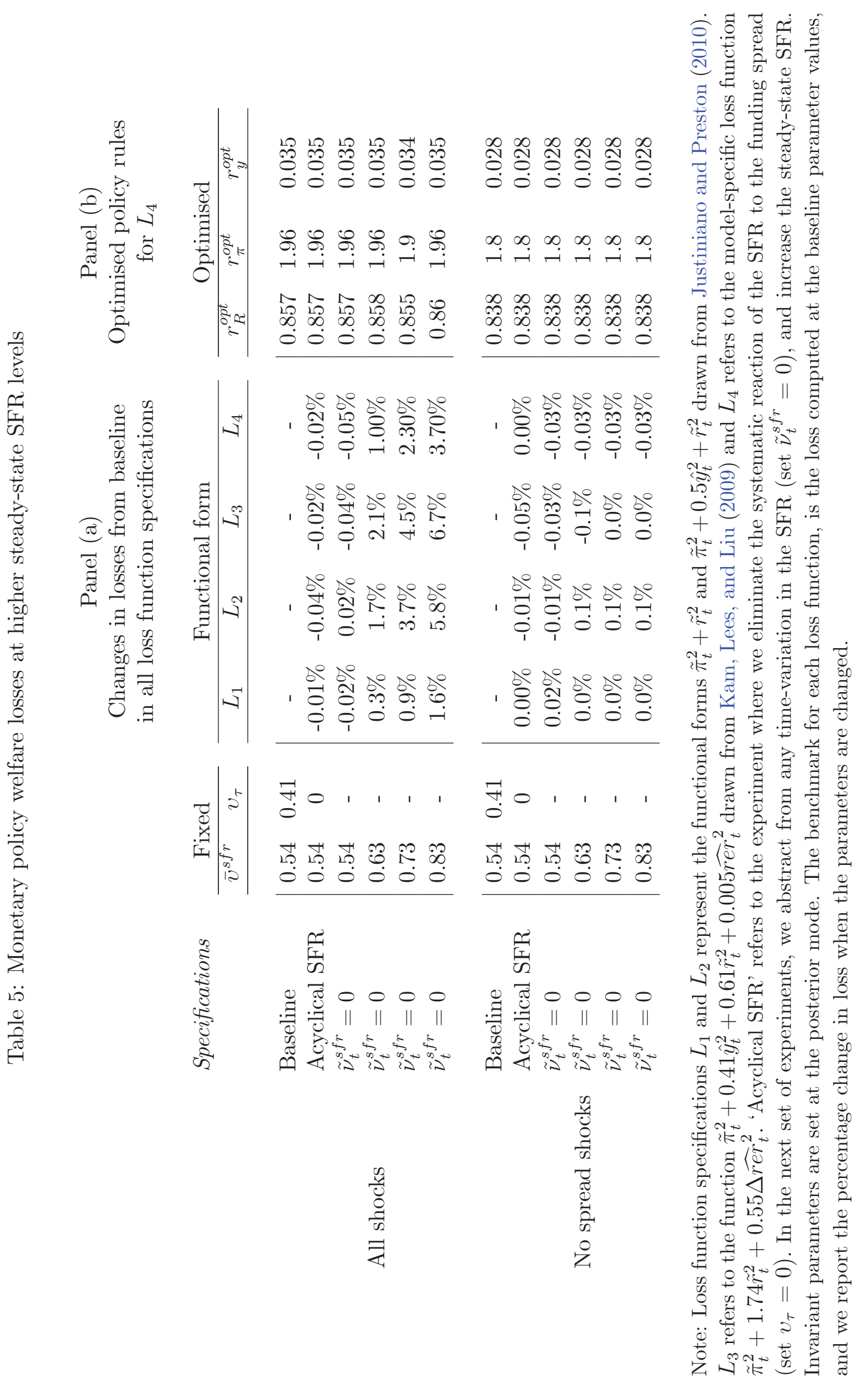




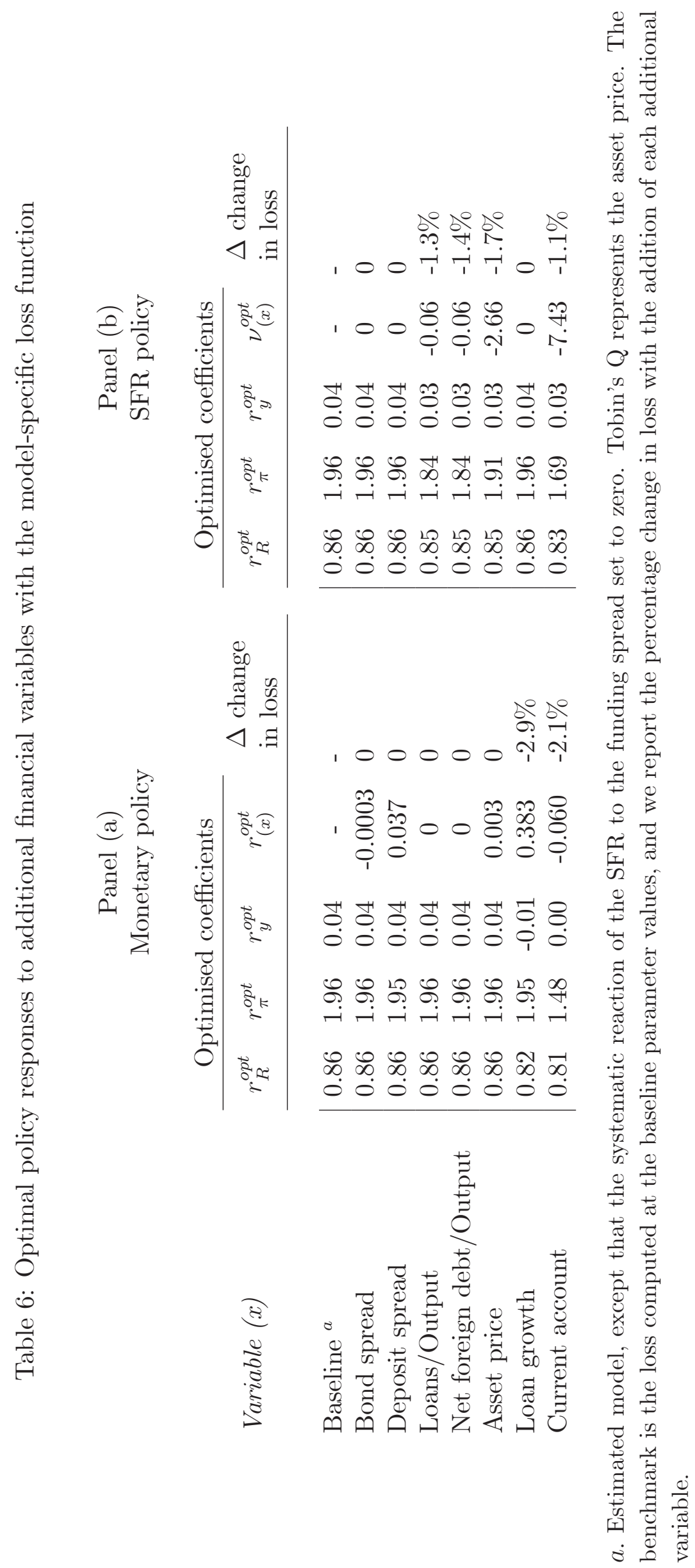




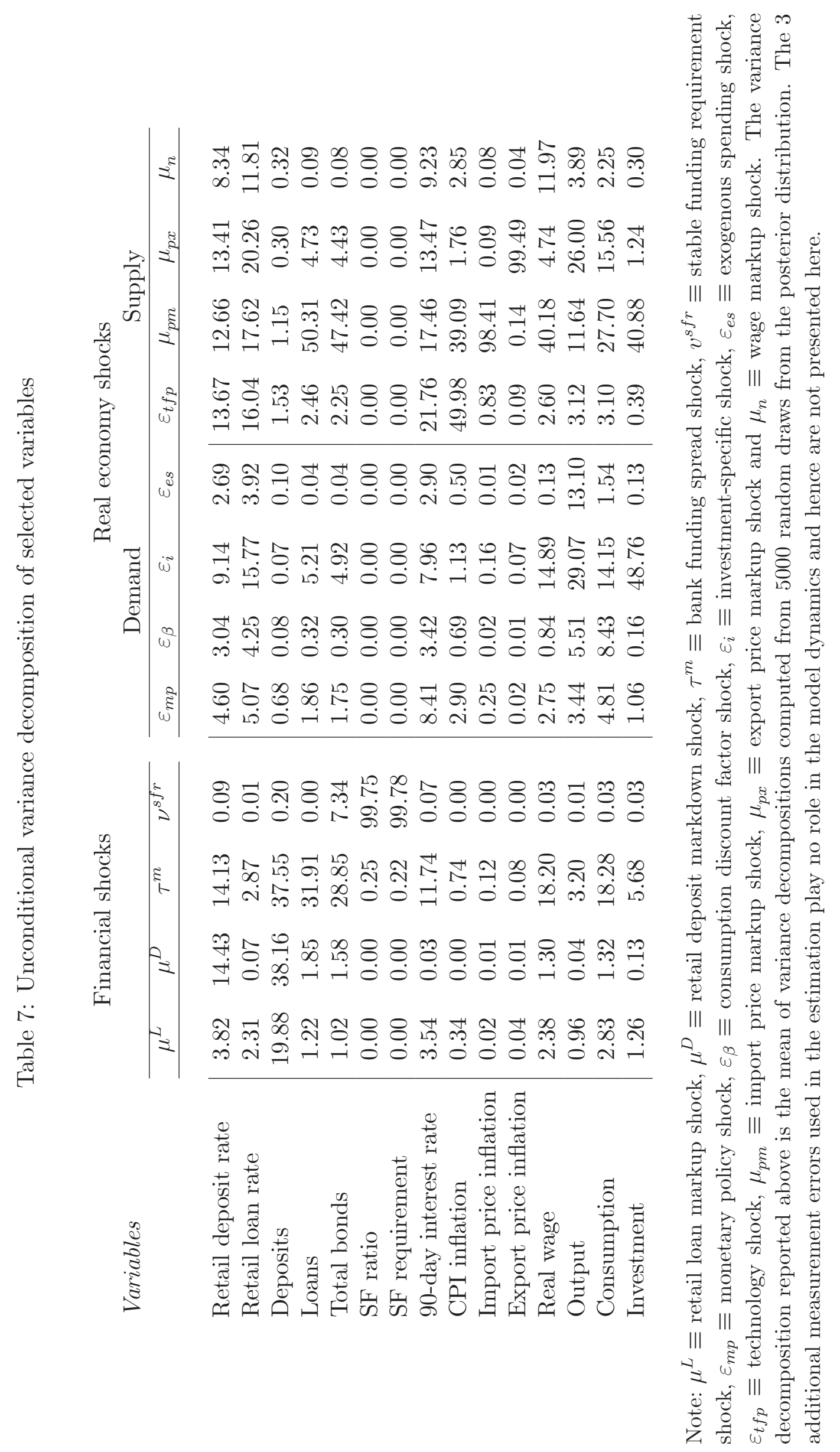




\section{A Other Equilibrium Conditions}

Here we list the optimality conditions for the non-banking segment of the model which were omitted from the main text. For brevity, we use gross interest rates and inflation notation: $R^{L}=1+r^{L}, \Pi_{c}=1+\pi_{c}, \Pi_{m}=1+\pi_{m}, \Pi_{x}=1+\pi_{x}$, and $\Pi^{n w}=1+\pi^{n w}$.

1. Consumption and investment CES aggregators:

$$
z_{t}=\left[\left(1-m_{z}\right)^{\frac{1}{\eta}} z_{d, t}^{\frac{\eta-1}{\eta}}+m_{z}^{\frac{1}{\eta}} z_{m, t}^{\frac{\eta-1}{\eta}}\right]^{\frac{\eta}{\eta-1}}, z \in\{c, i\},
$$

where $\eta>0$ and $m_{z} \in[0,1]$. The subscripts $d$ and $m$ indicate domestic and import sales respectively. The nominal price deflators for consumption and investment are given by:

$$
P_{z, t}=\left[\left(1-m_{z}\right) P_{d, t}^{1-\eta}+m_{z} P_{m, t}^{1-\eta}\right]^{\frac{1}{1-\eta}}, z \in\{c, i\} .
$$

The sales for domestic and imported components of consumption and investment $\left(c_{d}, i_{d}, c_{m}, i_{m}\right)$ and exports $\left(y_{x}^{*}\right)$ are given by:

$$
\begin{gathered}
z_{d, t}=\left(1-m_{z}\right)\left(\frac{P_{d, t}}{P_{z, t}}\right)^{-\eta} z_{t}, z \in\{c, i\}, \\
z_{m, t}=m_{z}\left(\frac{P_{m, t}}{P_{z, t}}\right)^{-\eta} z_{t}, z \in\{c, i\} \\
\text { and } y_{x, t}^{*}=\left(\frac{P_{x, t}}{P_{t}^{*}}\right)^{-\eta_{x}} y_{t}^{*}
\end{gathered}
$$

where $P^{*}$ and $y^{*}$ represent the aggregate price level and output in the foreign economy and $\eta_{x}>0$ is the price elasticity of the aggregated export good.

2. Euler equation for consumption $(c)$ :

$$
\left(c_{t}-\gamma_{c} c_{t-1}\right)^{-1}=\mathbb{E}_{t}\left(c_{t+1}-\gamma_{c} c_{t}\right)^{-1} \beta_{t} \frac{\varepsilon_{\beta, t+1}}{\varepsilon_{\beta, t}} \frac{R_{t}^{L}}{\Pi_{c, t+1}},
$$

where $\varepsilon_{\beta, t}\left(c_{t}-\gamma_{c} c_{t-1}\right)^{-1}=\lambda_{t}$ is the marginal utility of consumption (or wealth) and $\varepsilon_{\beta}$ is an intertemporal preference shock.

3. Euler equation for capital stock $(k)$ which determines the flow of Tobin's q $(t q)$ :

$$
t q_{t}=\mathbb{E}_{t} \beta_{t} \frac{\lambda_{t+1}}{\lambda_{t}}\left[r_{c, t+1}^{k}+t q_{t+1}\left(1-\delta_{k}\right)\right]
$$

where $\delta_{k} \in[0,1]$ is the depreciation of the capital stock.

4. Euler equation for investment $(i)$ :

$$
\varepsilon_{i, t} t q_{t}\left[1-\phi\left(\frac{i_{t}}{i_{t-1}}\right)-\frac{i_{t}}{i_{t-1}} \phi^{\prime}\left(\frac{i_{t}}{i_{t-1}}\right)\right]+\mathbb{E}_{t} \beta_{t} \frac{\lambda_{t+1}}{\lambda_{t}} t q_{t+1} \varepsilon_{i, t+1} \frac{i_{t+1}^{2}}{i_{t}^{2}} \phi^{\prime}\left(\frac{i_{t+1}}{i_{t}}\right)=\frac{P_{i, t}}{P_{c, t}}
$$


where $\varepsilon_{i}$ is a shock that stimulates the transformation of the investment good to physical capital.

5. Nominal wage inflation $\left(\Pi^{n w}\right)$ :

$$
\begin{aligned}
& \mathbb{E}_{t} \beta_{t} \frac{\lambda_{t+1}}{\lambda_{t}} \frac{1}{\Pi_{c, t+1}} \frac{n_{t+1}}{n_{t}} \frac{\left(\Pi_{t+1}^{n w}\right)^{2}}{\Pi_{c, t}^{\iota_{w}} \bar{\Pi}_{c}^{1-\iota_{w}}} \chi_{w}\left(\frac{\Pi_{t+1}^{n w}}{\Pi_{c, t}^{\iota_{w}} \bar{\Pi}_{c}^{1-\iota_{w}}}-1\right) \\
= & \frac{\Pi_{t}^{n w}}{\Pi_{c, t-1}^{\iota_{w}} \bar{\Pi}_{c}^{1-\iota_{w}}} \chi_{w}\left(\frac{\Pi_{t}^{n w}}{\Pi_{c, t-1}^{\iota_{w}} \bar{\Pi}_{c}^{1-\iota_{w}}}-1\right)+\vartheta_{n, t}\left[\begin{array}{c}
1-\frac{\chi_{w}}{2}\left(\frac{\Pi_{t}^{n w}}{\Pi_{c, t-1}^{\iota_{1}} \bar{\Pi}_{c}^{1-\iota_{w}}}-1\right)^{2} \\
-n_{t}^{\omega_{n}} \frac{\left(c_{t}-\gamma_{c} c_{t-1}\right)}{w_{c, t}}
\end{array}\right]-1,
\end{aligned}
$$

where $\Pi_{t}^{n w}=\frac{w_{c, t}}{w_{c, t-1}} \Pi_{c, t}$ and $\vartheta_{n}$ is a shock to the wage elasticity of labour demand.

6. Production function:

$$
y_{t}=\varepsilon_{t f p, t} k_{t-1}^{\alpha} n_{t}^{1-\alpha}, \alpha \in[0,1],
$$

where $\varepsilon_{t f p}$ is a neutral technology shock.

7. Substitution between factors of production obtained by combining labour and capital demand:

$$
\frac{r_{d, t}^{k} k_{t-1}}{\alpha}=\frac{w_{d, t} n_{t}}{1-\alpha}
$$

where the subscript $d$ indicates that the factor prices have been deflated by the output deflator $P_{d}$.

8. Real marginal cost:

$$
r m c_{d, t}=\frac{1}{\varepsilon_{t f p, t} \alpha^{\alpha}(1-\alpha)^{1-\alpha}}\left(r_{d, t}^{k}\right)^{\alpha} w_{d, t}^{1-\alpha}
$$

9. Domestic sales price inflation $\left(\Pi_{d}\right)$ :

$$
\begin{aligned}
& \mathbb{E}_{t} \beta_{t} \frac{\lambda_{t+1}}{\lambda_{t}} \frac{1}{\Pi_{c, t+1}} \frac{y_{t+1}}{y_{t}} \frac{\Pi_{d, t+1}^{2}}{\Pi_{d, t}^{\iota_{p d}} \bar{\Pi}_{d}^{1-\iota_{p d}}} \chi_{p d}\left(\frac{\Pi_{d, t+1}}{\Pi_{d, t}^{\iota_{p d}} \bar{\Pi}_{d}^{1-\iota_{p d}}}-1\right) \\
& =\frac{\Pi_{d, t}}{\Pi_{d, t-1}^{\iota_{p d}} \bar{\Pi}_{d}^{1-\iota_{p d}}} \chi_{p d}\left(\frac{\Pi_{d, t}}{\Pi_{d, t-1}^{\iota_{p d}} \bar{\Pi}_{d}^{1-\iota_{p d}}}-1\right)+\bar{\vartheta}_{d}\left[\begin{array}{c}
1-\frac{\chi_{p d}}{2}\left(\frac{\Pi_{d, t}}{\Pi_{d, t-1}^{c_{p d}} \bar{\Pi}_{d}^{1-\iota_{p d}}}-1\right)^{2} \\
-r m c_{d, t}
\end{array}\right]-1
\end{aligned}
$$

where $\chi_{p d} \geqslant 0$ measures the associated price adjustment cost and $\iota_{p d} \in[0,1]$ measures the degree of price indexation.

10. Export sales price inflation $\left(\Pi_{x}\right)$ :

$$
\begin{aligned}
& \mathbb{E}_{t} \beta_{t} \frac{\lambda_{t+1}}{\lambda_{t}} \frac{1}{\Pi_{c, t+1}} \frac{y_{x, t+1}}{y_{x, t}} \frac{n e r_{t}}{n e r_{t+1}} \frac{\Pi_{x, t+1}^{2}}{\Pi_{x, t}^{\iota_{p x}} \bar{\Pi}_{x}^{1-\iota_{p x}}} \chi_{p x}\left(\frac{\Pi_{x, t+1}}{\left.\Pi_{x, t}^{\iota_{p x}} \bar{\Pi}_{x}^{1-\iota_{p x}}-1\right)}\right. \\
= & \frac{\Pi_{x, t}}{\Pi_{x, t-1}^{\iota p x} \bar{\Pi}_{x}^{1-\iota_{p x}}} \chi_{p x}\left(\frac{\Pi_{x, t}}{\Pi_{x, t-1}^{\iota_{p x}} \bar{\Pi}_{x}^{1-\iota_{p x}}}-1\right)+\vartheta_{x, t}\left[\begin{array}{c}
1-\frac{\chi_{p x}}{2}\left(\frac{\Pi_{x, t}}{\Pi_{x, t-1}^{\iota p} \bar{\Pi}_{x}^{1-\iota_{p x}}}-1\right)^{2} \\
-\frac{n e r_{t} P_{d, t}}{P_{x, t}}
\end{array}\right]-1,
\end{aligned}
$$


where $P_{x}$ is the foreign-currency price set by the exporter for the domestic good, $\chi_{p x} \geqslant 0$ moderates the price adjustment cost, $\iota_{p x} \in[0,1]$ measures the degree of price indexation, and $\vartheta_{x}$ is a shock to the price elasticity (and markup) for export sales.

11. Import sales price inflation $\left(\pi_{m}\right)$ :

$$
\begin{aligned}
& \mathbb{E}_{t} \beta_{t} \frac{\lambda_{t+1}}{\lambda_{t}} \frac{1}{\Pi_{c, t+1}} \frac{y_{m, t+1}}{y_{m, t}} \frac{\Pi_{m, t+1}^{2} \chi_{p m}}{\Pi_{m, t}^{\iota_{p m}} \bar{\Pi}_{m}^{1-\iota_{p m}}}\left(\frac{\Pi_{m, t+1}}{\Pi_{m, t}^{\iota_{p m}} \bar{\Pi}_{m}^{1-\iota_{p m}}}-1\right) \\
= & \frac{\Pi_{m, t} \chi_{p m}}{\Pi_{m, t-1}^{\iota_{p m}} \bar{\Pi}_{m}^{1-\iota_{p m}}}\left(\frac{\Pi_{m, t}}{\Pi_{m, t-1}^{\iota_{p m}} \bar{\Pi}_{m}^{1-\iota_{p m}}}-1\right)+\vartheta_{m, t}\left[\begin{array}{c}
\left.1-\frac{\chi_{p m}}{2}\left(\frac{\Pi_{m, t}}{\Pi_{m, t-1}^{\iota_{p m}} \bar{\Pi}_{m}^{1-\iota_{p m}}}-1\right)^{2}\right]-1, \\
-\frac{P_{t}^{*}}{n e r_{t} P_{m, t}}
\end{array}\right]-
\end{aligned}
$$

where $y_{m}=c_{m}+i_{m}$ represents import sales volumes. $P^{*}$ is the price of the foreign good which is procured by the importer and sold in domestic currency. $\chi_{p m} \geqslant$ 0 measures the associated price adjustment cost and $\vartheta_{m}$ is a shock to the price elasticity (and markup) for imports.

12. Goods market clearing:

$$
y_{t}=c_{d, t}+i_{d, t}+y_{x, t}^{*}+\varepsilon_{e s, t}+A C_{p, t}+A C_{w, t},
$$

where $y_{x}^{*}$ indicates export sales volumes and $\varepsilon_{e s}$ is a shock to exogenous spending which includes government spending and changes in inventories. $A C_{p}$ and $A C_{w}$ are price and wage adjustment costs expressed in terms of the domestic good.

13. The SOE only has a negligible influence on the foreign country which is modelled as a closed economy, and specified using laws of motions for output $\left(y^{*}\right)$, inflation $\left(\Pi^{*}\right)$ and interest rate $\left(R^{*}\right)$ :

$$
\begin{aligned}
\left(y_{t}^{*}\right)^{-1} & =\mathbb{E}_{t}\left(y_{t+1}^{*}\right)^{-1} \beta^{*} \frac{R_{t}^{*}}{\Pi_{t+1}^{*}}, \\
\mathbb{E}_{t} \beta^{*} \frac{\lambda_{t+1}^{*}}{\lambda_{t}^{*}} \frac{y_{t+1}^{*}}{y_{t}^{*}} \frac{\Pi_{t+1}^{*}}{\bar{\Pi}^{*}} \chi^{*}\left(\frac{\Pi_{t+1}^{*}}{\bar{\Pi}^{*}}-1\right) & =\frac{\Pi_{t}^{*}}{\bar{\Pi}^{*}} \chi^{*}\left(\frac{\Pi_{t}^{*}}{\bar{\Pi}^{*}}-1\right)+\bar{\vartheta}\left[1-\frac{\chi^{*}}{2}\left(\frac{\Pi_{t}^{*}}{\bar{\Pi}^{*}}-1\right)^{2}-y_{t}^{*}\right]-1,
\end{aligned}
$$

and

$$
\frac{R_{t}^{*}}{\bar{R}^{*}}=\left(\frac{R_{t-1}^{*}}{\bar{R}^{*}}\right)^{r_{R}}\left(\frac{\mathbb{E}_{t} \Pi_{t+1}^{*}}{\bar{\Pi}^{*}}\right)^{\left(1-r_{R}\right) r_{\pi}}\left(\frac{y_{t}^{*}}{\bar{y}^{*}}\right)^{\left(1-r_{R}\right) r_{y}},
$$

where the parameters are given the same values as their analogues in the SOE.

\section{B Further Estimation Details and Results}

As mentioned in Section 3, we use 15 series to estimate the log-linearised SOE model. We use 15 shocks to link the model to the observed data. $12 \mathrm{AR}(1)$ structural shocks are embedded in the model: shocks to the loan markup $\left(\mu^{L}\right)$, deposit mark-down $\left(\mu^{D}\right)$, funding 
interest rate spread $\left(\tau^{m}\right)$, stable funding ratio $\left(v^{s f r}\right)$, monetary policy $\left(\varepsilon_{m p}\right)$, consumption discount factor $\left(\varepsilon_{\beta}\right)$, business investment $\left(\varepsilon_{i}\right)$, exogenous spending $\left(\varepsilon_{e s}\right)$, technology $\left(\varepsilon_{t f p}\right)$, import price markup $\left(\mu_{p m}\right)$, export price markup $\left(\mu_{p x}\right)$ and wage markup $\left(\mu_{n}\right)$. As in Smets and Wouters (2007), the shocks are rescaled to enter the estimation with a unit coefficient. In addition, we use $3 \mathrm{AR}(1)$ measurement errors in the observation equations for loan growth $\left(m e^{\Delta \ell}\right)$, deposit growth $\left(m e^{\Delta d}\right)$ and bond growth $\left(m e^{\Delta b}\right)$. We use 1,000,000 iterations of the Random Walk Metropolis Hastings algorithm to simulate the posterior distribution and achieve an acceptance rate of about 22 percent. The first 500,000 draws are discarded. We monitor the convergence of the marginal posterior distributions using trace-plots, CUMSUM statistics as well as the partial means test as in Geweke (1999). The test statistics confirm that all parameter estimates converge. To reduce the autocorrelation between the draws, we retain only every $75^{\text {th }}$ iteration. Posterior parameter moments, impulse response functions and simulated moments of the endogenous variables are computed from 5000 parameter vectors randomly drawn from the thinned chain.

In Figure 5, we compare the volatilities of the data series used in the estimation with the analogous volatilities generated from the SOE model when parameters are set at values randomly drawn from the posterior distribution. The model captures the unconditional volatilities of the variables fairly well: the data moments lie within or very close to the $95 \%$ probability set generated from the model in most cases. The fit is particularly striking for export price inflation and the policy rate. On the downside, the model over-predicts the volatilities of CPI inflation and output growth, the former more so than the latter. We continue the validation exercise in Figure 6 which compares the autocorrelation functions of the observed variables with their model analogues. The data moments mostly lie within the probability bands generated by the model and the match is rather striking for the stable funding ratio, retail deposit and loan rates and export price inflation. The SOE model is only modestly successful in tracking the autocorrelation of the growth rates of the real and financial quantities. It does not capture the pattern of persistence observed in the data although the data moments are within the limits of the credibility bands from the model at most horizons.

Table 7 reports the unconditional volatility decomposition of selected variables in the banking sector and the real economy. The structural disturbances have been loosely clas- 
sified into financial and real-economy shocks, the latter being further disaggregated into demand-type and supply-type shocks. A striking feature of the variance decomposition is that financial sector disturbances have little quantitative impact on the real economy variables such output, inflation, interest rate and aggregate demand. ${ }^{26}$ In stark contrast, real-economy disturbances play a more prominent role in explaining the volatility of the banking sector variables. Financial shocks have little effect on the real economy because the external bond market is estimated to be very liquid, and because the effect on the loan rate of a rise in external funding costs is moderated by substitution toward domestic deposit funding and higher deposit spreads. In contrast, real disturbances have a substantial effect on financial variables. In particular, technology shocks and cost-push shocks to import and export prices and wages matter for fluctuations in the banking sector variables. These disturbances contribute more than half the volatility of the retail deposit and loan interest rates. The marginal utility of consumption is an important factor driving the household's decisions to borrow and to save. Interestingly, the banking sector shocks play a subdued role in determining the dynamics of the retail interest rates. The SFR and observed stable funding ratio are driven mostly by the exogenous component of the SFR rule.

\footnotetext{
${ }^{26} \mathrm{An}$ exception is the funding spread shock which contributes roughly $18 \%$ of consumption volatility in the long run. The spread shock is the most persistent of all the estimated disturbances, and hence plays a prominent role in the asymptotic variance decomposition presented here. In the short-run impulse response analysis, we observe that the spread shock generates weaker consumption dynamics than one standard deviation impulses from other real-economy shocks.
} 